\title{
Microdroplets in Microfluidics: An Evolving Platform for Discoveries in Chemistry and Biology
}

Ashleigh B. Theberge, Fabienne Courtois, Yolanda Schaerli, Martin Fischlechner, Chris Abell, Florian Hollfelder, and Wilhelm T. S. Huck*

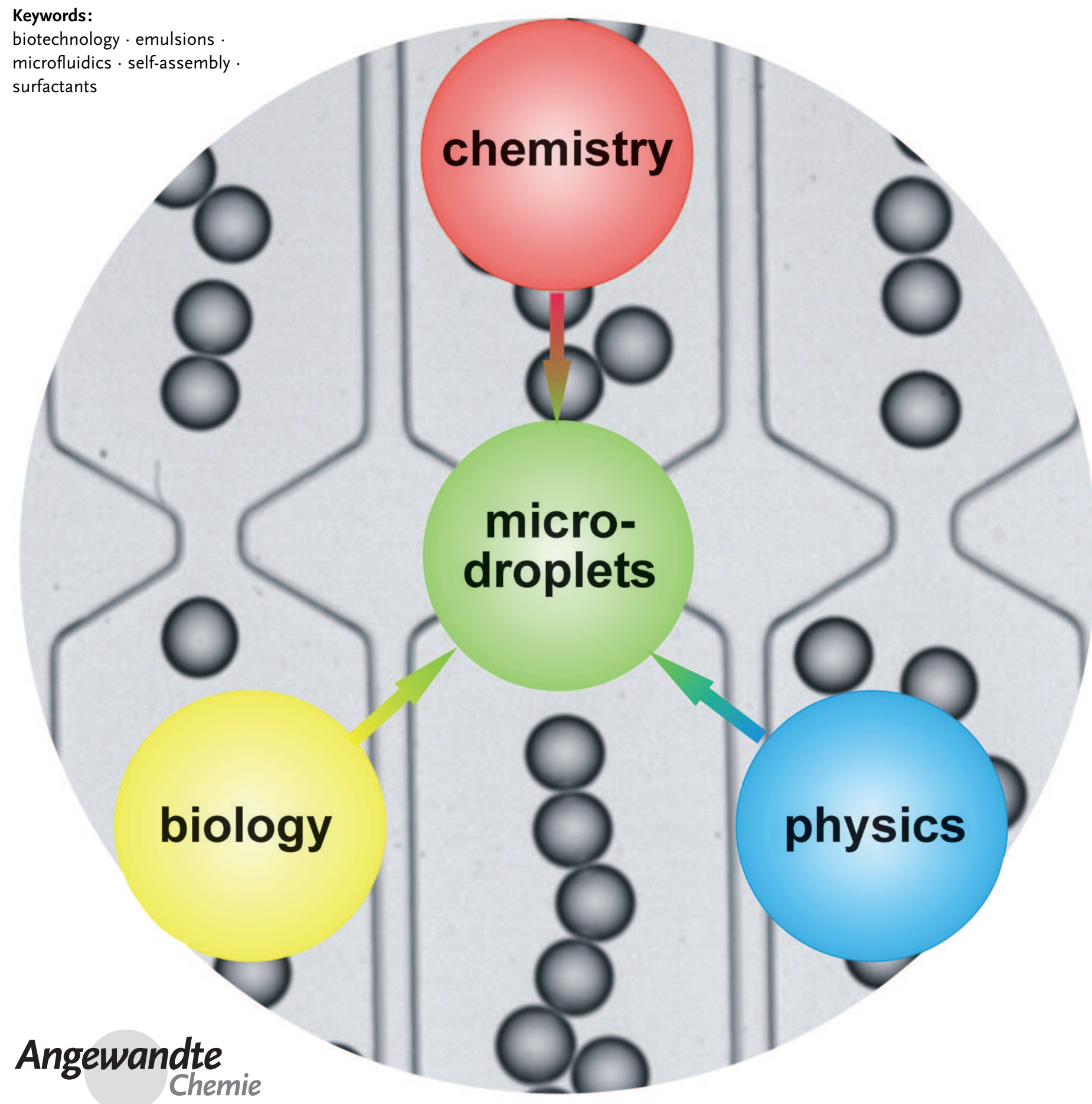


$M i$ in chemical and biological research. They provide a compartment in which species or reactions can be isolated, they are monodisperse and therefore suitable for quantitative studies, they offer the possibility to work with extremely small volumes, single cells, or single molecules, and are suitable for high-throughput experiments. The aim of this Review is to show the importance of these features in enabling new experiments in biology and chemistry. The recent advances in device fabrication are highlighted as are the remaining technological challenges. Examples are presented to show how compartmentalization, monodispersity, single-molecule sensitivity, and high throughput have been exploited in experiments that would have been extremely difficult outside the microfluidics platform.

\section{Introduction}

In 1954, Joshua Lederberg published a "simple method for isolating individual microbes". ${ }^{[1]}$ Extending de Fonbrune's oil chamber method of spraying water droplets into mineral oil ${ }^{[2]}$ he demonstrated the compartmentalization of single cells into nanoliter droplets. Just a few years later, Nossal and Lederberg published their seminal Nature paper proving the "one-cell-one-antibody" rule. ${ }^{[3]}$ Their experimental technique involved the isolation of single lymph-node cells which were then carefully washed, and maintained in microdroplets under mineral oil for several hours to allow for a substantial antibody concentration to be reached. Bacteria were then introduced and the ability of the cells to influence bacterial survival was monitored under a microscope. ${ }^{[4]} \mathrm{A}$ few years later, Rotman published a groundbreaking paper studying single enzyme kinetics in droplets by simply dispersing a very dilute aqueous solution of $\beta$-D-galactosidase into droplets in oil and measuring conversion by fluorescence microscopy (Figure 1). ${ }^{[5]}$

Lederberg envisaged applications of microdroplets for any study that required small culture volumes and hoped that his method would "find routine applications in any laboratory". However, although the basic ideas of compartmentalization of cells and the study of enzymatic reactions in microdroplets were demonstrated, it has taken almost 50 years for Lederberg's vision to become reality. Partially, this is because those experiments were extremely laborious and throughput very slow, with only a few hundred experiments done over a ten year period. Furthermore, digital cameras did not exist and fluorescence detection was much less sensitive than current techniques. Also, only with the advent of the -omics era has a much more apparent need arisen for being able to carry out experiments at the smallest possible scale (if possible single cells or molecules), on a massively parallel platform and with high throughput. Recent advances in microfluidics have created powerful tools for micromanipulation of small volumes in lithographically fabricated, and hence extremely reproducible and well defined fluidic chips. This combination has resulted in a rapidly growing community of researchers studying reactions

\section{From the Contents}

\begin{tabular}{l} 
1. Introduction \\
$\begin{array}{l}\text { 2. Key Characteristics of the } \\
\text { Microdroplets in Microfluidics } \\
\text { Platform }\end{array}$ \\
$\begin{array}{l}\text { 3. Technological Bottlenecks and } \\
\text { Advances }\end{array}$ \\
$\begin{array}{l}\text { 4. Online Characterization of } \\
\text { Reactions in Droplets }\end{array}$ \\
$\begin{array}{l}\text { 5. Cells in Droplets } \\
\text { 6. In Vitro Transcription/ } \\
\text { Translation }\end{array}$ \\
\hline 7. Polymerase Chain Reaction \\
(PCR) in Droplets \\
\hline 8. Small-Molecule Synthesis in \\
Droplets
\end{tabular}

in microdroplets in microfluidics (also called "biphasic", "segment", or "plug-based" microfluidics). ${ }^{[6]}$ This area of microfluidics is different from so-called "digital microfluidics" where discrete droplets, typically in air, are addressed individually using electrowetting. Digital microfluidics provides unparalleled control over droplet manipulation, but at the cost of much smaller numbers of droplets and significantly more complicated device fabrication. ${ }^{[7,8]}$

In this Review, we will only consider microdroplets in microfluidics, where in essence, each droplet is analogous to the traditional chemist's flask, with the added physical advantages of reduced reagent consumption, rapid mixing, automated handling, and continuous rather than batch processing. ${ }^{[9-11]}$ Following on from previous comprehensive Reviews on droplets in microfluidics, ${ }^{[6,12-14]}$ we will focus on

[*] A. B. Theberge, Dr. F. Courtois, Y. Schaerli, Dr. M. Fischlechner Prof. Dr. C. Abell, Prof. Dr. W. T. S. Huck Department of Chemistry, University of Cambridge Lensfield Road, Cambridge, CB2 1EW (UK) E-mail:wtsh2@cam.ac.uk

Dr. F. Courtois, Y. Schaerli, Dr. F. Hollfelder Department of Biochemistry, University of Cambridge 80 Tennis Court Road, Cambridge, CB2 1GA (UK) Prof. Dr. W. T. S. Huck

Radboud University Nijmegen, Institute for Molecules and Materials Heyendaalseweg 135, 6525 AJ Nijmegen (The Netherlands) E-mail:w.huck@science.ru.nl 

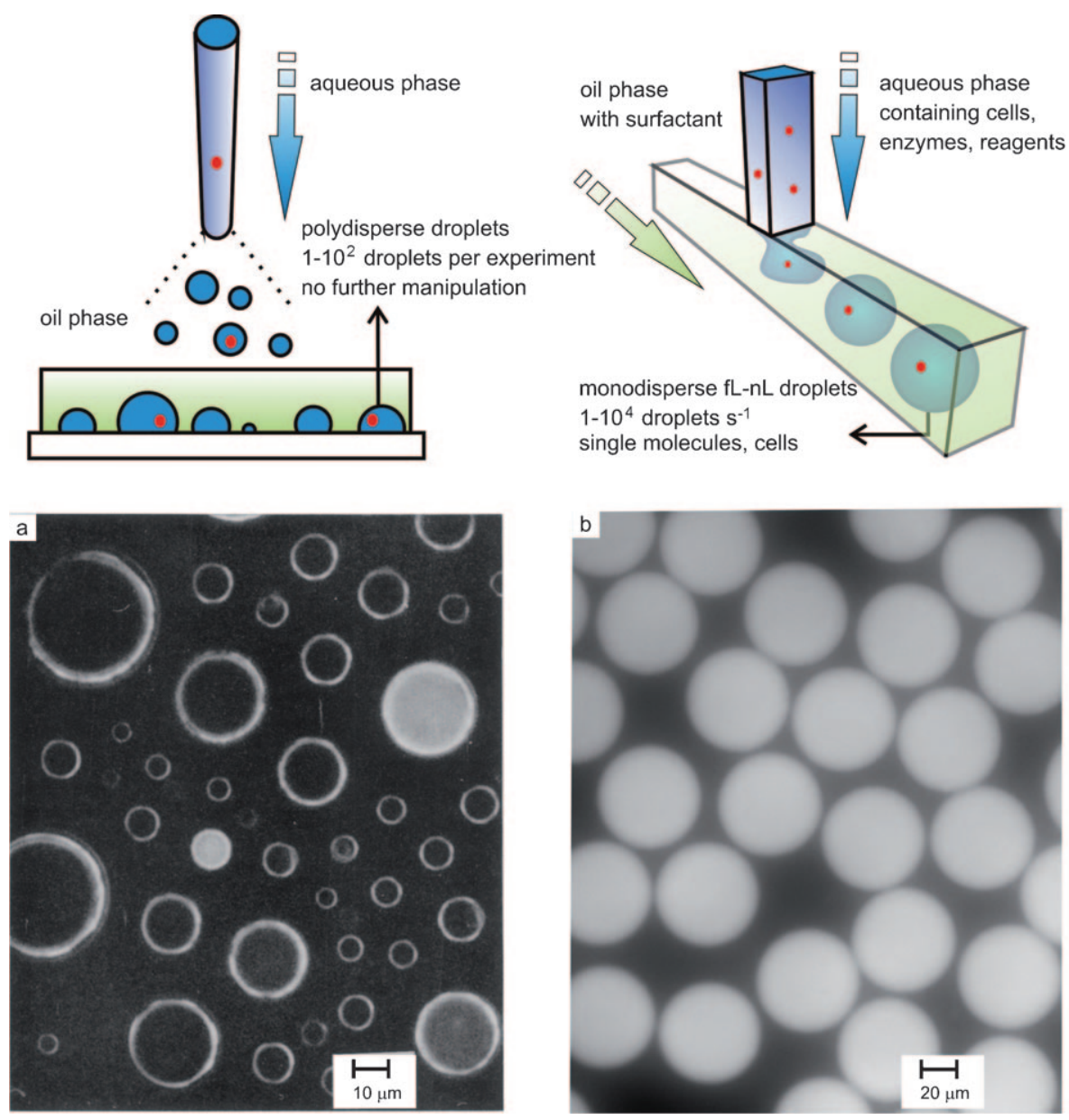

partmentalized reactions at the femtoliter, single cell, or indeed single molecule level. The key features of microdroplets in microfluidics are that they 1) provide a compartment in which species or reactions can be isolated, 2) are monodisperse and therefore potentially suitable for carrying out quantitative studies, 3) provide the possibility to work with extremely small volumes and single cells or molecules and, 4) offer the ability to perform very large numbers of experiments. Herein we summarize the importance of these specific features in enabling new experiments in biology and chemistry. We will highlight the recent advances in device fabrication that have enabled such experiments and address the remaining technological challenges that lie ahead. We will also discuss in detail the most prominent examples of how compartmentalization, monodispersity, single-molecule sensitivity, and high-throughput have been exploited in experiments that would have been extremely difficult outside the microfluidics platform.

Figure 1. Top: Schematic of droplet formation with conventional techniques (left) or a microfluidic platform (right). Micrographs (a) and (b) show the outcome of each technique. a) Rotman's classic experiment on single-enzyme kinetics using microdroplets dispersed in oil. Reproduced with permission from Ref. [5]. b) Monodisperse $\mathrm{fL}$ to $\mathrm{nL}$ droplets from a microfluidics platform for biological and chemical experiments.

\section{Key Characteristics of the Microdroplets in Micro- fluidics Platform}

the recent developments in the field, taking into account the significant increase in complexity of the microdroplet devices and the impressive range of tools that have been employed to study the contents of droplets, leading to new applications.

Lederberg and Rotman convincingly demonstrated that microdroplets offer an enabling technology to study com-

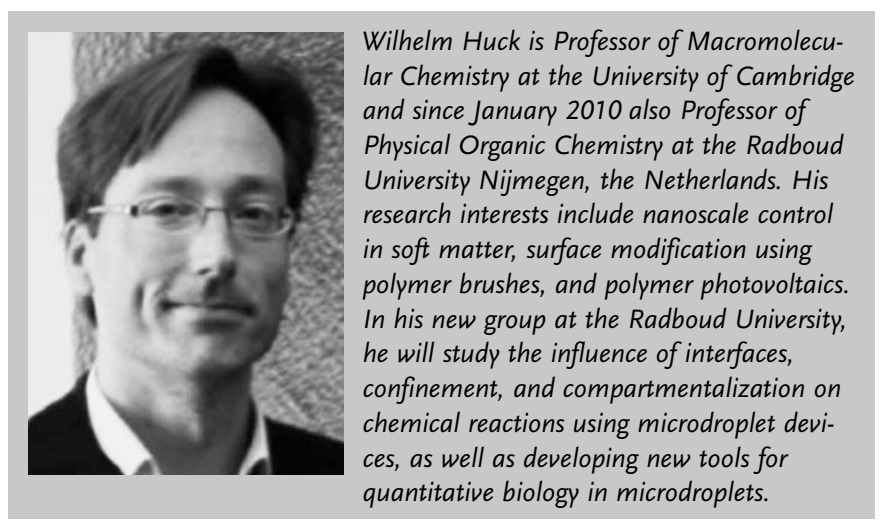

\subsection{Compartmentalization}

The general concept of compartmentalization of chemical reactions, that is, of reactions occurring in closed vessels, in this case a microdroplet, can be applied to a very wide range of experiments where each microdroplet contains all the ingredients for an experiment and will contain the outcome of this experiment. This situation is not limited to the molecular level, and experiments have been designed with droplets containing cells and even living organisms, where the environment of the cell can be controlled and measurements on changes in solute concentrations can be associated with specific events inside the cell. Essentially, microdroplets partition experiments into individual microscopic compartments, separated from each other by an immiscible carrier phase. The commercially most successful application of microdroplets (in bulk emulsions) is emulsion polymerase chain reaction (PCR), which is used, for example, for the Genome Sequencer FLX (Roche) and SOLiD (ABI), socalled "next generation" high-throughput sequencing systems. ${ }^{[15,16]}$ Several microfluidics-based platforms for PCR experiments in droplets have recently been reported, see 
Section 7. A suitable illustration of what can be achieved using microdroplets (although not in microfluidic devices but using bulk emulsions) is the in vitro compartmentalization ${ }^{[17]}$ of phenotype and genotype. Genotype and phenotype are linked, not by compartmentalization of genes in cells, but by compartmentalization in aqueous microdroplets in water-inoil emulsions. Indeed, emulsion droplets have been used to select proteins for binding, and for catalysis from large gene libraries (ca. $10^{9}$ members) ${ }^{[18,19]}$ and the evolution of DNA polymerases with new properties. ${ }^{[20,21]}$ This concept was introduced into a microfluidic platform by the compartmentalization of both plasmid DNA and a commercially available in vitro transcription and translation system in aqueous microdroplets. The integrated devices could form droplets and store droplets for hours, which enabled protein expression from a single molecule of DNA template, creating "monoclonal droplets" in which genotype and phenotype were combined in one emulsion compartment. ${ }^{[22]}$

\subsection{Quantitative Measurements with Monodisperse Droplets}

Early schemes for experiments in droplets suffered from a major inherent drawback of emulsions: the droplets were polydisperse. As a result, every experiment took place in a different volume and therefore the reaction conditions rapidly diverged, because the concentration of reagents and reaction products could not be controlled without volume control. It was therefore difficult to quantitatively compare emulsion droplet-based experiments and although screening or decision-making processes based on the readout of the droplets were possible, it was at a less stringent level than perhaps desirable. In contrast, microdroplets prepared on a microfluidics platform are highly monodisperse, with polydispersities in the range of $1 \%$ (in diameter). ${ }^{[23,24]}$ Furthermore, the analysis of reactions in bulk emulsions by screening individual droplets takes a considerable amount of time and therefore every droplet is analyzed at a different reaction time. In a microfluidic format, the screening is not much faster, but the rank order of droplets can be maintained and so every droplet has the same time lag between formation and screening. Additionally, droplets can be analyzed directly onchip using integrated techniques, such as fluorescence detection, so they can be interrogated at controlled times. The advantage of a microfluidics platform is crucial: as monodisperse droplets are formed on-chip and reactions are initiated at the point of drop formation or by droplet fusion, every droplet is identical both in terms of concentrations as well as "history". The ability to directly compare droplets has an important advantage in single-cell or single-molecule studies, where stochastic variations require the detailed analysis and combination of data from large numbers of experiments. ${ }^{[25]}$

\subsection{Small and Sensitive}

Typical droplet volumes are in the femtoliter to nanoliter range $\left(10^{-15}\right.$ to $\left.10^{-9} \mathrm{~L}\right)$. As a result, reagent consumption is extremely small, allowing for the screening and analysis of precious compounds. Controlling the volume of droplets and the ability to tune the concentration of salts and macromolecules in droplets also provides an ideal platform for exploring optimum conditions for protein crystallization. ${ }^{[26,27]}$ The large surface-to-volume ratio of droplets and the internal flows induced by shear interactions and differential flow speeds of carrier fluid and droplets, offers extremely efficient mass and heat transfer between the carrier phase and the internal phase. ${ }^{[28]}$ The chemical analysis of small droplets moving through channels at high frequencies is a challenge and, as discussed in Section 4, new developments in analytical tools are required. It should be noted that working with very small amounts does not necessarily mean that samples are dilute. In the case of the compartmentalization of single cells in droplets, confinement increases cell density and also allows released molecules to accumulate around the cell. Therefore, their concentration rapidly increases, which reduces the time required to detect the released molecules.

\subsection{Large Numbers, Fast Reactions}

Most publications describing experiments in microdroplets in microfluidics report typical droplet formation frequencies in the range of 0.1 to $2 \mathrm{kHz}$. Such rates would give perfectly high resolution data when studying enzymatic reactions occurring in droplets, or in cell-based screening experiments. There is a strong drive to push droplet formation in microfluidics to the frequency range that would be compatible with the screening rate of modern flow cytometers which can screen and sort up to 70000 cells per second. The ability to fuse droplets by electrocoalescence, for example, has been used to control the precise combination of reagents. ${ }^{[29]}$ Fusion occurs in less than $100 \mu \mathrm{s},{ }^{[30]}$ resulting in a small dead time of the "instrument", although the subsequent time for mixing of reagents, even aided by passing them through a winding channel where chaotic advection creates a homogeneous solution, takes several milliseconds. ${ }^{[9,31]}$

\section{Technological Bottlenecks and Advances}

The intense research activity in the area of microdroplets in microfluidics during the past 5 years has resulted in a range of methods for forming, fusing, and sorting small droplets, and this aspect of droplet research is beginning to mature (Figure 2). Several Reviews and Feature articles present an extensive overview of the technological and engineering aspects of this area of research. ${ }^{[6,14,32-35]}$ For complex (bio)chemical, or biological experiments to be carried out in a microdroplets format, devices will require a high level of integration. Herein, we review developments in droplet manipulation by considering the challenges and bottlenecks that remain in place before more complex experiments can be implemented. Integration of different modules requires droplet formation and manipulation to be extremely wellcontrolled. Furthermore, most experiments require additional manipulation such as separation and purification steps. 

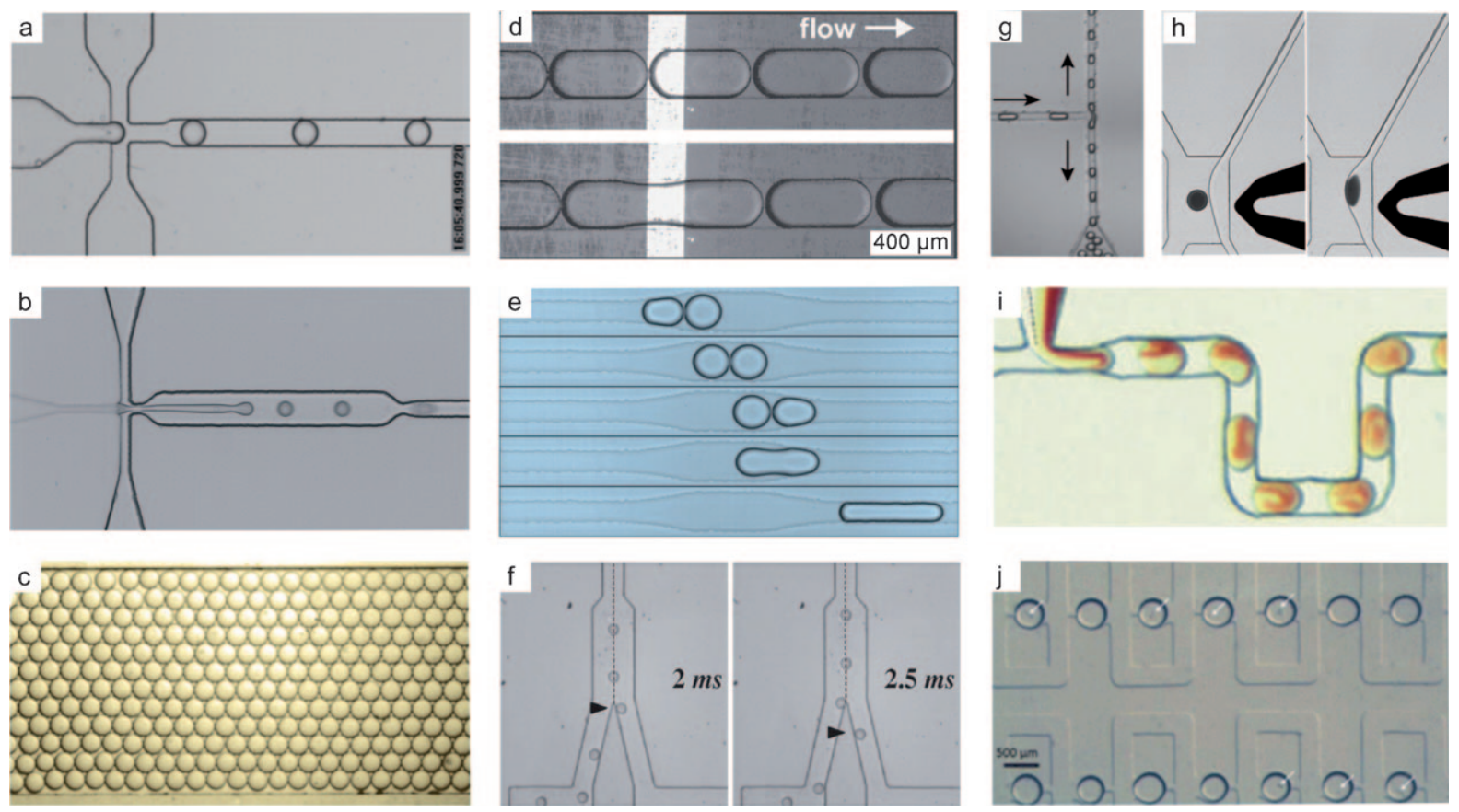

Figure 2. An overview of commonly used droplet-manipulation modules. a) Droplet formation in a flow-focusing device. b) Droplet formation from jetting in a flow-focusing device. c) Delay line/storage area. Reproduced with permission from Ref. [74]. d) Droplet fusion by electrocoalescence. Reproduced with permission from Ref. [30]. e) Passive, channel-geometry-mediated droplet fusion. Reproduced with permission from Ref. [81]. f) Electrosorting of droplets. Reproduced with permission from Ref. [113]. g) Channel-geometry-mediated droplet splitting. Image reproduced with permission from Ref. [37]. h) Electric-field-induced emulsion separation. Reproduced with permission from Ref. [119]. i) Mixing the contents of droplets in a winding channel. Reproduced with permission from Ref. [31]. j) Droplet storage. Reproduced with permission from Ref. [61].

Finally, a range of analytical tools is required to study the contents of droplets quantitatively at very high throughput and with very high sensitivity. In the next Section, a number of key areas of technological challenges and bottlenecks that are crucial to integrated droplet devices are discussed from the perspective of experiments that could be carried out in droplet-based microfluidic devices.

\subsection{Droplet Generators}

Droplet formation using T-junctions ${ }^{[23,36,37]}$ or flow-focusing devices ${ }^{[38]}$ are two well-established methods for forming monodisperse $(<1-3 \%$ dispersity) droplets at rates up to around $10 \mathrm{kHz}$. Garstecki and co-workers ${ }^{[39]}$ showed that the dynamics of breakup in a confined geometry of a microfluidic flow-focusing device is entirely controlled by the rate of supply of the continuous fluid to the region in which the break-up occurs. Uniform droplets are produced in such devices by the uniform times of collapse of the liquid thread generated in the nozzle as a result of the slow progression of collapse and the fast equilibration of the interfacial tension and hydrostatic pressure fields.

Several groups have explored the break-up of jets as potential routes to form droplets. Utada et al. ${ }^{[40]}$ studied in detail two different classes of dripping-to-jetting transitions in co-axial flows; one driven by increasing the flow rate of the continuous phase, the other by increasing the flow rate of the internal phase. Qualitatively, these regimes are very different, with the former leading to a jet of decreasing size along the channel, which eventually breaks into small droplets, and the latter leading to much larger droplets that bead off at the end of a widening jet. Forming monodisperse droplets using jetting is challenging, but is possible to adjust the flow parameters and channel dimensions such that an absolute instability is always achieved, leading to controlled breakup. ${ }^{[41]}$ Another way to initiate droplet formation from a jet is by introducing additional confinement in the channel. When a stable jet encounters a constriction in the channel, the inner fluid breaks into drops, in either a dripping or jetting regime. ${ }^{[42]}$

The use of jetting regimes has pushed droplet formation rates into the $10 \mathrm{~s}$ of $\mathrm{kHz}$ regime, which offers a significant advance in throughput when designing screening experiments. However, as mentioned, for screening of large libraries or for sorting cell populations in droplets, rates of at least an order of magnitude higher are desirable. Furthermore, the total volume of emulsion produced remains small. Droplet formation rate therefore becomes a limiting step in areas such as on-chip particle formation. ${ }^{[43]}$ The rate of droplet formation can be increased by many orders of magnitude using membranes or sieves to produce many droplets simultaneously. Membrane emulsification produces droplets by dispersing one fluid into a continuous phase through a membrane or sieve, essentially forming an array of T-junctions. ${ }^{[44]}$ By using non-cylindrical pores, the phase to be dispersed is forced to assume a distorted (elongated) disk-like shape on the terrace in the microchannel. This distorted shape has a 
higher interfacial area with at least one radius of curvature smaller than a spherical shape in the well. As a result, droplet size is entirely controlled by the pore size $(1-50 \mu \mathrm{m}) .^{[45,46]}$

An often overlooked, but potentially extremely disrupting phenomenon in microdroplets in microfluidic devices is the unstable droplet formation during the initial filling of microfluidic devices as a result of constantly changing backpressure. ${ }^{[47]}$ Any changes in flow rate affect droplet frequency, composition, size, and speed. Consequently, the devices produce polydisperse droplets until the flows stabilize and monodisperse droplets are produced. For devices containing in-channel droplet traps (see Section 3.5) or when working with small volumes of precious reagents, a more reliable method for droplet formation needs to be established.

When high throughput is not required, "on-demand" droplet formation can be a route to ensuring that only perfectly monodisperse droplets enter the device. "Ondemand" droplet generation can be achieved using sudden changes in applied pressure in combination with narrow channels at the flow-focusing section of a device and rapid withdrawal of the water flow from a budding droplet. ${ }^{[48,49]}$ Chiu and co-workers also generated single water droplets in oil with volumes on the order of femtoliters to picoliters in microfluidic channels using short $(\mathrm{ms})$, high voltage $(\mathrm{kV})$ electric pulses to deflect the aqueous/oil interface. ${ }^{[50]}$ This deflection resulted in the formation of an aqueous jet that breaks off into a droplet because of Rayleigh instability. The size of the droplet formed is determined by the amplitude and duration of the pulse and the dimension of the microchannel. ${ }^{[51]}$ Alternatively, an on-chip piezo-electric actuator can be used to give very high control over droplet formation. ${ }^{[52]}$ Additional control over droplet size, independent of device geometry and flow rates, can be achieved by the introduction of local heating elements. Changes in temperature lead to changes in interfacial tension and viscosity, allowing modulation of the droplet diameter formed in a flow focusing device. ${ }^{[53,54]}$

\subsection{Compartmentalizing Reagents}

As already demonstrated by Rotman and Lederberg, simple dilution is an effective means of ensuring that single enzymes or cells are compartmentalized in droplets. A similar approach is effective in a microfluidics platform, and has been shown for cells, ${ }^{[5,56]}$ DNA molecules, ${ }^{[57,58]}$ and whole organisms. ${ }^{[59-61]}$ The dilution approach is not suitable for small molecules as there is no amplification step to demonstrate their function, as is possible, for example, with DNA-from which many proteins can be expressed including enzymes that can turnover many substrate molecules into prod- uct molecules. It is therefore extremely challenging to create a library of unique droplets each containing a different member of that library. Chiu and co-workers have proposed an elegant first step towards solving this problem. ${ }^{[62,63]}$ By coupling the aqueous inlet of a microfluidic device with the outlet of a capillary electrophoresis column, mixtures can potentially be separated and plugs containing pure compounds can subsequently be compartmentalized in droplets. Alternatively, droplets containing solutes of interest can be formed and subsequently stored, only to be used when required. Thus, by taking aliquots of many such stored droplets, experiments requiring droplets with different contents can be carried out. Following this approach, Raindance Technologies demonstrated an optically encoded droplet library for screening a drug library for its cytotoxic effect against U937 cells. ${ }^{[64]}$

Passive compartmentalization of single cells or particles from dilution leads to a Poisson distribution of empty droplets, droplets with one cell, two cells, etc. Inevitably, this distribution leads to a large fraction of empty droplets and a loss in productive throughput. However, by exploiting a cell-triggered Rayleigh-Plateau instability in a flow-focusing geometry, Chabert and Viovy demonstrated single-cell compartmentalizing during jet break-up. Although the rate of droplet formation was relatively slow $\left(10^{2}\right.$ per second $), 70$ $80 \%$ of the injected cell population was encapsulated into drops containing one and only one cell, with $<1 \%$ contamination by empty droplets. ${ }^{[65]}$ Toner and co-workers ${ }^{[66]}$ reported single-cell compartmentalization by relying on cells to self-organize prior to droplet formation (Figure 3). Self-organization occurs when a high density suspension of cells or particles is forced to travel rapidly through a high aspect-ratio microchannel, for which the particle diameter is a large fraction of the channel's narrow dimension. Owing to the even spacing of cells or particles in the channel, the droplet formation coincides with a cell entering the flow-

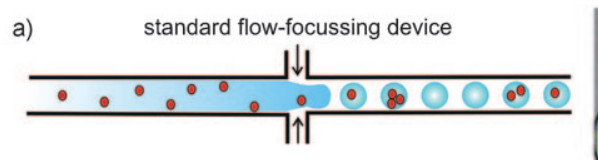

b)

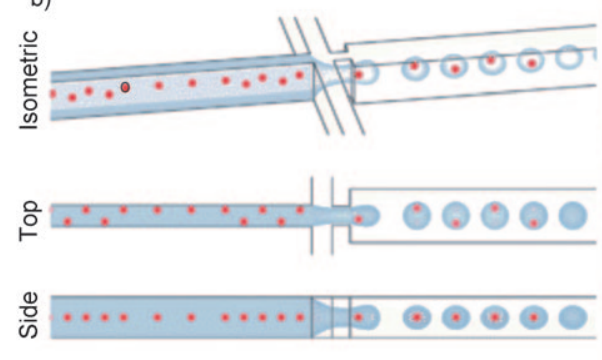

Figure 3. A method for beating Poisson statistics: single-particle droplets. a) Random or Poisson encapsulation leads to empty droplets, droplets containing single-particle drops (circles) and multiple-particle drops (boxes). b) hydrodynamic interactions cause particles to self-organize along one side of the microchannel or into a diagonal/alternating pattern. The uniform spacing of particles in the direction of flow (see side view) leads to the formation of single-particle drops when the two lateral flows of oil pull drops from the aqueous stream (see isometric view) with the same (or higher) frequency that particles reach the microdrop generator. Ordered encapsulation of beads generates more single-particle and fewer empty droplets than would have been possible from stochastic (Poisson) loading. Scale bar: $200 \mu \mathrm{m}$. Reproduced with permission from Ref. [66]. 
focusing region and virtually every drop contains exactly one cell, thereby overcoming the intrinsic limitations set by Poisson statistics. The idea of pre-ordering particles or cells to control the encapsulation efficiency can be extended to gelbead encapsulation. ${ }^{[67]}$ Soft gel particles either plug the nozzle thereby triggering droplet formation and concomitant compartmentalization, or particles are first close-packed and subsequently loaded into water-in-oil droplets using devices that also form efficient multiple and hierarchical emulsions. ${ }^{[68]}$

The compartmentalization of single cells into small droplets is an effective method for increasing cell density. During compartmentalization a dilute solution is divided into many small parts (droplets), most of which are empty, and some containing a single cell. A cell in a picoliter droplet amounts to a much higher concentration than the original cell suspension. The compartmentalization forced by the droplet allows released molecules to accumulate around the cell, reducing the time required to detect the molecules released by the cells. This system has been used to monitor the sensitivity of methicillin-resistant Staphylococcus aureus (MRSA) to several antibiotics in a single experiment, and to measure the minimal inhibitory concentration (MIC) of cefoxitin against this strain. ${ }^{[69]}$

\subsection{Surfactants}

Although the term "microdroplet" is used to refer to droplets with micron dimensions, the colloidal dispersion that results is a macroemulsion and is by definition metastable. Droplet formation does not require surfactants, but without stabilizing agents, droplets rapidly coalesce inside the devices. Even with surfactants, droplets are not necessarily completely sealed containers, as small molecules can diffuse through the surfactant layer into the oil, depending on the nature of the surfactant, as well as the hydrophilicity or lipophilicty of the molecules compartmentalized inside droplets. ${ }^{[70]}$ The choice of which surfactant to use depends both on the nature of continuous phase (typically hydrocarbon or fluorocarbon oils for water-in-oil emulsions) and the planned experiments inside the droplets under investigation. For mineral oils, commercially available surfactants, such as Span 80 and Abil EM have been most widely used, whereas Krytox (DuPont), which contains a perfluoropolyether (PFPE) tail and a carboxylic acid hydrophilic head group, has been used with fluorous oil continuous phases. Fluorinated oils confer many advantages over conventional hydrocarbon oils, such as improved oxygen permeability and immiscibility with organic compounds, but until recently fluorinated surfactant options for microdroplet experiments were limited. In the last few years, however, activity in the area of fluorinated surfactant synthesis and characterization has lead to a variety of novel surfactants for improved droplet stability and biocompatibility, vastly expanding the range of possible biological and chemical experiments possible with the microdroplet platform.

b)

c)
With each biological experiment biocompatibility of the reagents has to be tested anew. For examples, oligoethylene glycol-terminated surfactants prevent non-specific adsorption of protein to the water-oil interface. ${ }^{[71]}$ This is an important consideration as the large surface-to-volume ratio can strongly affect the outcome of enzymatic reactions in droplets. Droplets produced by splitting from bigger droplets lead to a redistribution of surfactants at the interface and therefore the changes the passivation of the interface against non-specific protein binding. The activity of $\beta$-galactosidase compartmentalized in large and small droplets was shown to decrease with droplet size as a result of higher adsorption and inactivation of the enzyme at the interface. ${ }^{[72]}$ Controlled protein adsorption at the droplet interface can be used to investigate mechanisms of protein aggregation important for the understanding of amyloid diseases. Capitalizing on the controlled aqueous-fluorous interfaces possible with dropletbased microfluidics, the aggregation of $A \beta_{40}$ was monitored in droplets with a fluorous-aqueous interface protected by a OEG fluorinated surfactant designed to prevent protein adsorption. ${ }^{[73]}$ Aggregation kinetics were decreased by at least an order of magnitude, indicating that this could be an effective method for minimizing interfacial effects when studying other factors affecting protein aggregation.

The effect of different hydrophilic head groups (Figure 4) on the biocompatibility of PFPE surfactants as has been investigated by Clausell-Tormos et al. ${ }^{[60]}$ Surfactants containing the ammonium salt of carboxy-PFPE and poly-L-lysine as head groups effected lysis of HEK293T in cells, whereas a)

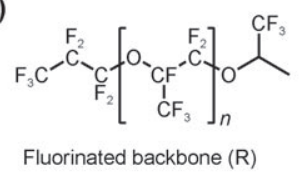<smiles></smiles>

Ammonium salt PFPE

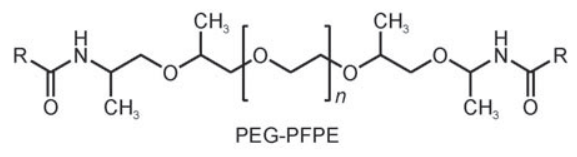<smiles>[R]C(=O)NCCCCC(NC(=O)C(CCCC[NH3+])NC(=O)C(CCCC[NH3+])NC(=O)C1C(N)C1CCCC[NH3+])C(=O)O</smiles>
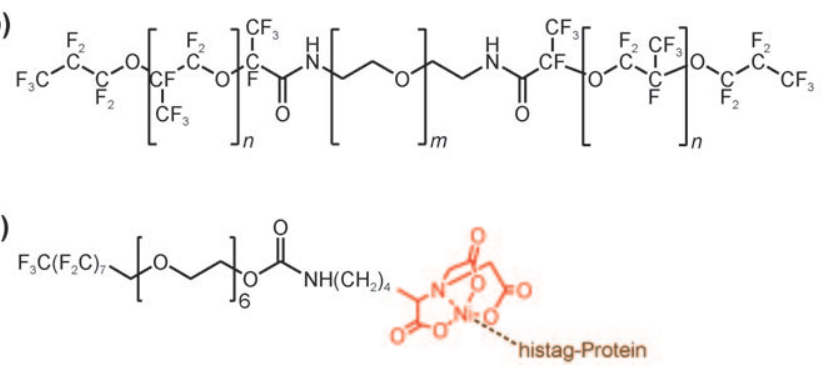

Figure 4. Fluorinated surfactants that improve biocompatibility and droplet stability as well as increasing protein concentration at the droplet surface. Figure adapted from Refs. [60], [74], and [75]. 
surfactants bearing polyethyleneglycol (PEG) and dimorpholinophosphate (DMP) allowed cultures to develop and proliferate in a similar fashion to control cells grown without surfactant. Using the DMP-PFPE surfactant in fluorinated oil, cells were encapsulated in droplets on a microfluidic chip and the emulsion was stored for up to 14 days off chip. Strikingly, the droplets could then be re-injected into a microfluidic device with minimal coalescence $(<10 \%$ after 14 days), indicating that the surfactant provided excellent stability in addition to biocompatibility. Holtze et al. ${ }^{[74]}$ synthesized a series of PEG-PFPE surfactants designed to balance several competing requirements for forming and stabilizing droplets for microfluidic applications. The PEG and PFPE components of the surfactant must be large enough to form dense brushes at the droplet interface to confer droplet stability and prevent coalescence, but at the same time the surfactant molecule must be small enough to diffuse quickly through the oil and assemble at the interface as droplets are formed at rates of $1-10 \mathrm{kHz}$. Additionally, surfactants with a critical micelle concentration (CMC) of $10^{-4} \mathrm{molL}^{-1}$ or greater are most efficient at assembling at the droplet interface. After a series of emulsion stability tests with different length PEG and PFPE segments, it was found that the surfactant synthesized from $600 \mathrm{~g} \mathrm{~mol}^{-1}$ PEG and $6000 \mathrm{~g} \mathrm{~mol}^{-1}$ PFPE (Figure 4) performed optimally allowing the formation of stable droplets at rates up to $30 \mathrm{kHz}$ and reinjection of droplets after storage off chip. The surfactant was also biocompatible, allowing both in vitro transcription and translation of plasmid DNA and cultivation of yeast and mammalian cells within droplets.

By incorporating a nitrilotriacetate (NTA) nickel complex head-group into a $\mathrm{C}_{8}$ fluorous tail surfactant by means of an OEG linker (Figure 4c), surfactants have been used to create droplet interfaces capable of concentrating histidine-tagged proteins at the droplet interface. ${ }^{[75]}$ This effect was visualized using His-tagged Green Fluorescent Protein (hGFP), and fluorescence recovery after photobleaching (FRAP) studies indicated that the interface was still laterally mobile, an advantage of this system over conventional self-assembled monolayers (SAMs). The increased concentration of proteins at the droplet interface resulted in a local supersaturation and was used to facilitate crystallization of a 6-histidine-tagged membrane protein in droplets.

Microfluidics offers precisely timed control over droplet manipulation events, and this has been used to study the timescales of surfactant passivation of interfaces. ${ }^{[76]}$ By using devices with different channel lengths between the droplet generation point and a subsequent channel widening designed to test for coalescence, it is possible to determine the amount of time required for surfactant assembly at the droplet interface. The dynamic movement of surfactants in microdroplet systems has also been tracked by using a surfactant that becomes fluorescent when the head group is positioned at the aqueous interface. The timescales at which surfactant adsorption occurs is in the millisecond to second range, which can easily be accommodated by creating short delay channels prior to further droplet modules. In related work, Wang et al. demonstrated how changes in the dynamic interfacial tension can affect droplet size. Working with hexane/water-Tween 20 , they note that droplet size decreased with increasing Tween 20 concentration up to the threshold for saturated adsorption. This work underscores the importance of surfactant adsorption on the droplet formation process. ${ }^{[77]}$ Building on an understanding of surfactant adsorption dynamics, Mazutis et al. ${ }^{[78]}$ devised a technique for droplet fusion that capitalizes on controlling droplet surface chemistry by tuning the surfactant concentration and surfactant accumulation time on chip. The goal was to create a system for passive fusion of droplet pairs that produced a stable fused droplet. They first generated stable droplets that could be incubated off chip and later re-injected using $4 \mathrm{wt} \%$ EA surfactant, a fluorinated surfactant available from RainDance Technologies (Lexington, MA), in fluorinated oil (FC-40). These surfactant-stabilized droplets were re-injected into a chip where unstable droplets were formed using $0.55 \mathrm{wt} \% \mathrm{EA}$ in FC40, a concentration high enough to allow for reproducible droplet formation, but not to entirely prevent droplet coalescence upon contact. Pairs formed from stable reinjected droplets and unstable newly formed droplets assembled on chip and were fused using a zigzag channel geometry. Interestingly, they found that carefully timed injection of stabilizing oil (2.8 wt \% EA in FC40) allowed sufficient surfactant to assemble at the interface of the one-to-one fused droplets to prevent undesired further coalescence but did not assemble in time to prevent the initial and desired coalescence of the paired droplets. This work provides an excellent example of how understanding the dynamics of surfactant adsorption can afford a specific microfluidic outcome.

\subsection{Initiating a Reaction in Droplets: Fusion}

Droplet fusion is a fundamental tool for the control of microdroplets in microfluidic devices and their use as microreactors, as it allows the precise mixing of reagents at welldefined points in space and time. The microfluidics platform enables very fast and reproducible mixing at the same time, which can be advantageous for reactions such as nanoparticle formation. ${ }^{[79]}$ Passive fusion devices rely on channel properties to induce droplet coalescence. In-channel droplet fusion is initiated when two or more droplets are brought into close contact by draining of the continuous phase. ${ }^{[80]}$ Imbalances in surface tension will then lead to coalescence. A detailed analysis of this process was described by Bibette and coworkers. ${ }^{[81]}$ In their device, the first droplet slows down before entering a more narrow section of a channel and then fuses with the second droplet in the sequence. Counterintuitively, coalescence with the incoming droplets occurs as the droplets begin to separate from each other and not during the initial impact. Separation induces the formation of two facing nipples in the contact area that hastens the connection of the interfaces prior to fusion. Moreover, droplet pairs initially stabilized by surfactants can be destabilized by forcing the separation. Most fusion devices have focused entirely on the fusion of two droplets only, which leaves the coalescence of any larger number of droplets in a controllable fashion out of reach of current device designs. Fidalgo et al. ${ }^{[82]}$ described a method for fusing microdroplets with surface energy patterns 
inside microfluidic channels, which disrupt the flow of droplets, trapping them to the pattern and only releasing them after coalescence. Varying channel and pattern dimensions as well as fluid flows can provide full control over droplet fusion, allowing the incorporation of several components into a single, large droplet by coalescence of multiple droplets. The disadvantage of this method is the potential for cross-contamination from the surface pattern. Niu et al. ${ }^{[83]}$ further developed in-channel fusion by incorporating rows of pillars within the channels that act as passive merging elements. The pillars trap droplets while allowing the continuous phase to drain when a second droplet enters the pillar area. The merging process was independent of the interdroplet separation but rather dependent on the droplet size. Moreover, the number of droplets that can be merged at any time is also dependent on the mass flow rate and volume ratio between the droplets and the merging chamber.

Active fusion methods have the advantage that the fusion process can be switched on or off, but they require accurate droplet synchronization as the droplets need to be in very close proximity. ${ }^{[84]}$ Active fusion devices rely on an external trigger to induce coalescence increasing the complexity of the device fabrication. Typically, fusion modules involve the use of strong electric fields ${ }^{[30,85-88]}$ or localized heating induced by laser pulses. ${ }^{[89]}$ The efficiency of electrocoalescence relies on the droplets to be fused being in close proximity, ${ }^{[29,90,91]}$ although a recent report showed a cascade of droplet coalescence against the flow direction at high electric fields. ${ }^{[92]}$ Smaller drops move faster because of the Poiseuille flow, this feature can be exploited to pair two different sized droplets by ensuring they are in contact in the region where they are coalesced with an electric field. For practical applications, these two droplets need to contain the reagents required to initiate the reaction and therefore robust methods for the formation of controlled sequences of droplets are required. Hydrodynamic coupling between two dropletformation channels ensures perfectly alternating droplet sequences. ${ }^{[93]}$ Hydrodynamic resistance can be exploited to synchronize droplets in two parallel channels by using passive devices such as loops or ladders, ${ }^{[94,95]}$ to ensure perfect alternation of droplets into two channels at a T-junction thus leading to symmetric splitting of droplet trains. ${ }^{[96,97]} \mathrm{A}$ remarkable effect of the bypassed T-junction is the reduction of noise in the system, leading to more perfectly spaced droplets in the devices. ${ }^{[98]}$

Droplet fusion with a surface as demonstrated by the "chemistrode" device is a new way of delivering reagents to the wetting layer on a solid surface and compartmentalizing molecules released from that same surface. ${ }^{[99]}$ Surfaces can be probed with chemical pulses as short as $50 \mathrm{~ms}$. Combining the chemistrode with fluorescence imaging, the utility of the technique was demonstrated by optically monitoring the increase of calcium produced by mouse islets loaded on a plate (surface) in response to the stimulation by a high concentration of glucose in droplets. ${ }^{[100]}$

\subsection{Running the Experiment: Increasing Residence Times}

Typical residence times for droplets in microfluidic devices are in the range of seconds to minutes, which means that they are not suitable for studying processes which occur on a timescale of minutes to hours, which would be typical for many chemical reactions as well as biological experiments involving the incubation of cells or the in vitro expression of proteins. The most straightforward method for increasing the residence times is to simply increase the channel length. Unfortunately, delay lines lead to a proportional increase in back-pressure, disrupting droplet formation and causing delamination of poly(dimethyl siloxane) (PDMS) layers. Frenz et al. have solved this problem by fabricating devices in which the delay line is deeper and wider than the droplet formation section. Additionally, they used periodic channel constrictions to stochastically mix the droplets ensuring that all droplets at a given point have similar residence times, thus avoiding the common problem that droplets in the center of the channel move faster than those at the edges. ${ }^{[101]}$ Shim et al. ${ }^{[102]}$ fabricated multilayer devices where droplets are trapped in sections of channels with slightly higher aspect ratios, leading to a minimization of the surface-tension forces around the droplets (which become more spherical). Precise control of the filling and retrieval of these in-line wells was achieved by on-chip valves which necessitated rather complex multilayer device fabrication. ${ }^{[103]}$ A major advantage of these multilayer devices is the option of precisely controlling the droplet volume over time. PDMS-based devices suffer from slow "evaporation" of aqueous droplets because of the water permeability of PDMS, ${ }^{[104,105]}$ as well as the uptake of water by the carrier phase. Shim and co-workers ${ }^{[102]}$ ensured the constant volume of the trapped droplets by adding a reservoir channel underneath the droplet storage area that contained water of the same molarity. Water permeating to and from the reservoir through a PDMS membrane allowed the droplet volume to be controlled.

Although this multilayer approach gives full fluidic control over droplet volumes, the fabrication of these devices is complex. A range of devices that are much more straightforward to fabricate has been reported. Courtois et al. described the design of an integrated device allowing precisely controlled formation of water-in-oil droplets, their storage for several hours in a reservoir, and individual analysis of droplets by laser detection. ${ }^{[2]}$ The reservoir, effectively a very wide section of a channel that can hold up to $10^{6}$ droplets, has a V-shaped entrance that causes the droplets to slow down gradually as they enter the chamber, thereby avoiding droplet fusion upon collision. To avoid sagging of the PDMS, four supporting pillars in the middle of the reservoir were inserted. These large reservoirs have the disadvantage that the precise position of each droplet is not controlled and that the original sequence of droplets is lost. The position of the trapped droplets can be controlled by introducing posts that capture droplets in the reservoir. ${ }^{[105]}$ Weitz and co-workers ${ }^{[106]}$ demonstrated a droplet array that can be used to monitor thousands of individual, picoliter-scale samples over time. Droplets flow through an array of round chambers connected by narrow constrictions: when there is flow, drops squeeze 
through the constrictions; in the absence of flow, surface tension drives the droplets to their lowest energy shape and ensures a single drop per chamber. Droplets can be recovered by simply increasing the carrier flow rate. These so-called dropspot devices were used to monitor $\beta$-galactosidase activity from over 200 single-cell-containing droplets by fluorescence imaging (Figure 5). As a result of the small volumes of the droplets, they also provide a controlled environment for nucleation events, which is important for a detailed study into the thermodynamic processes that generate desirable crystal structures, ${ }^{[107,108]}$ or the rapid screening of solubility diagrams. ${ }^{[109]}$

Takeuchi and co-workers developed trapping devices composed of square-wave shaped loop channels superimposed onto a straight channel, with the narrowed regions along the straight channel functioning as traps. The channels are designed such that when a trap is empty, the straight channel has a lower flow resistance than that of the loop channel. As a result, the bulk of the fluid flows along the straight channel. A particle or droplet in the flow will be carried into the trap (trapping mode) and then acts as a plug, increasing the flow resistance drastically along the straight channel, and redirecting the main flow to the loop channel. Subsequent particles or droplets will then be carried along the loop channel, bypassing the filled trap (bypassing mode). ${ }^{[110]}$ The same design was employed by Shi et al. to trap droplets containing C. elegans, ${ }^{[61]}$ whereas Fraden and co-workers use a modified design to "park" and generate droplets. ${ }^{[11]}$

Finally, a novel and effective near-instantaneous droplet trapping method was reported using a single, automated, twoposition valve. ${ }^{[12]}$ This approach eliminates droplet motion thus allowing optical interrogation of the droplets in singlemolecule detection applications and enabling assessment of chemical reaction kinetics with millisecond resolution.

\subsection{Sorting droplets}

Droplet sorting is an essential module for integrated devices to separate "active" droplets from the rest of the droplet stream. Electric fields have been used extensively to deflect droplets by dielectrophoresis into a separate channel, while non-deflected droplets travel along the path of least hydrodynamic resistance. ${ }^{[113]}$ Surface acoustic wave devices have also been embedded in microfluidic devices and are capable of deflecting droplets or particles by locally compressing fluids. ${ }^{[14]}$ Alternatively, magnetic fields have been used to manipulate droplets loaded with magnetic parti- a)

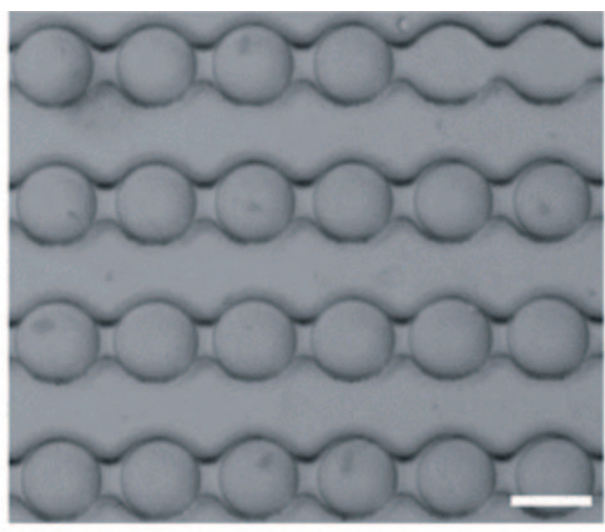

b)

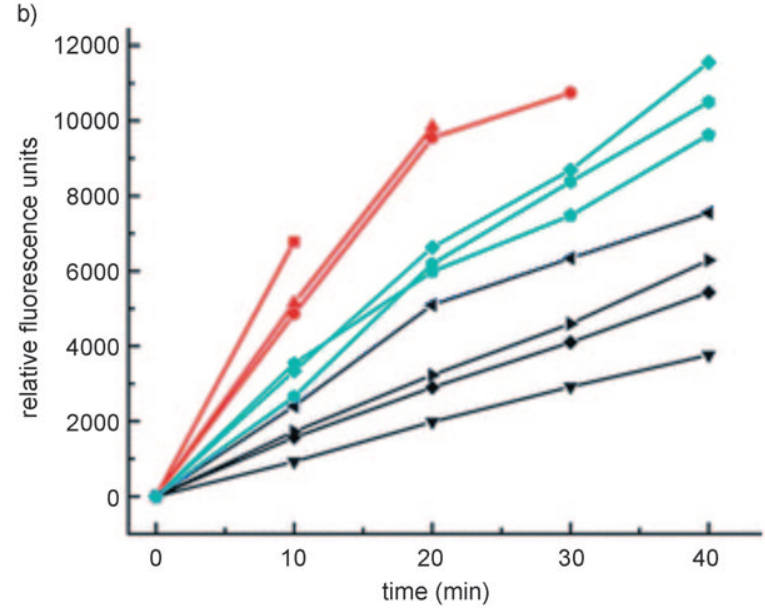

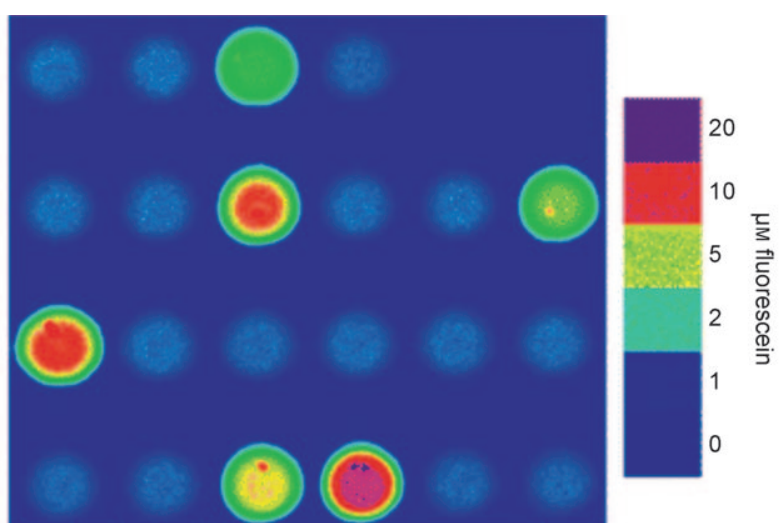

c)

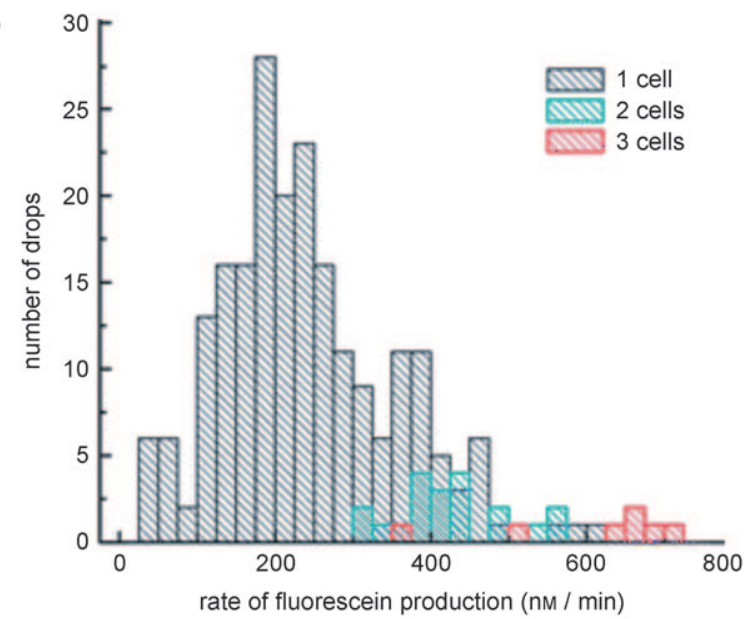

Figure 5. "Dropspot" arrays to monitor the fluorescence intensity of drops containing a fluorogenic substrate and cells producing $\beta$-galactosidase. a) Brightfield image and color map gradient of a fluorescence image at $t=45 \mathrm{~min}$. Scale bar $40 \mu \mathrm{m}$. b) Changes in drop fluorescence over time. Plots for 9 individual representative drops containing 1 (black), 2 (cyan), and 3 (red) cells. c) Reaction rates for 265 drops containing cells, the number of cells per drop is also displayed. Reproduced with permission from Ref. [106]. 
cles, ${ }^{[115]}$ and laser-induced localized heating offers another way to sort droplets. ${ }^{[89,116]}$ Integration of a microheater offers precise control over droplet motion (leading to both splitting and sorting of droplets) at Y-junctions through changes in fluidic resistance and the thermocapillarity in one of the branches. ${ }^{[117]}$

The electric signal obtained from fluorescence light detected at a photon multiplier tube can be used to trigger further droplet manipulations. This feature has been applied to sort droplets selectively based on their fluorescent content in a manner similar to a flow cytometer. Baret et al. encapsulated single E. coli cells in picoliter droplets and used an enzymatic assay with a fluorescent product to determine the presences or absence of $\beta$-galactosidase activity. Electric fields triggered by the fluorescence signal were then used to sort $\beta$-galactosidase positive mutants at a rate of $300 \mathrm{~Hz}$ and the emulsion containing intact cells was recovered and analyzed by colony screening (Figure 6). The maximum sorting efficiency of fluorescein droplets achieved to date is comparable to results obtained with a FACS (fluorescence-activated cell sorting) displaying a false positive
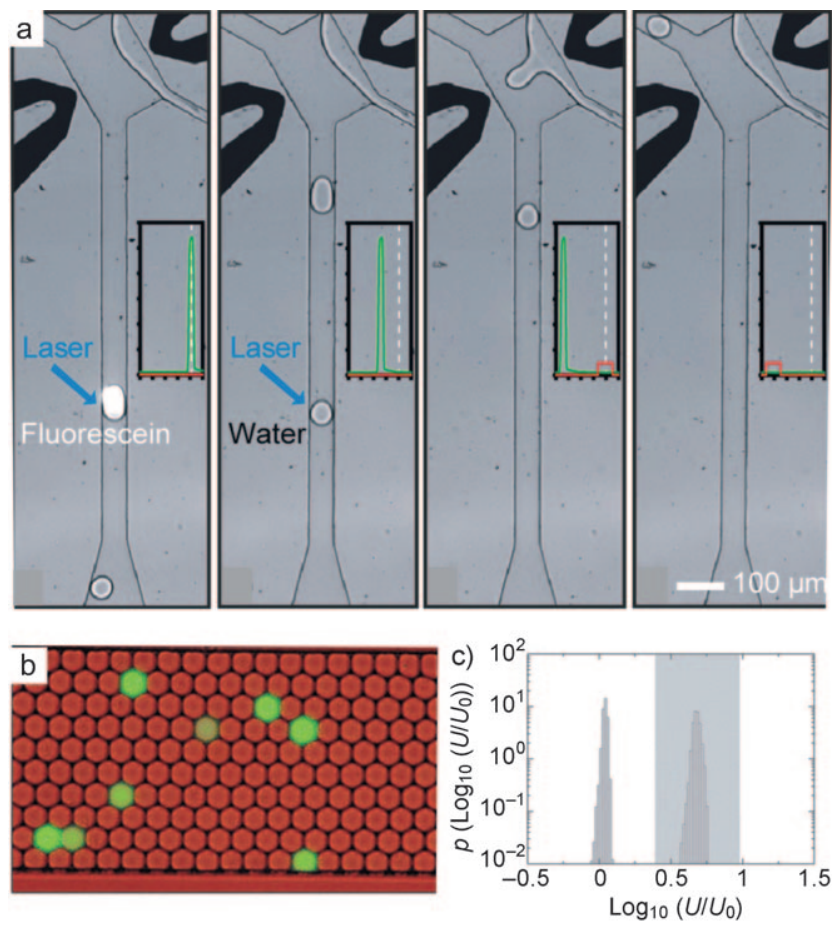

Figure 6. a) Micrographs showing the selection and extraction of a fluorescent droplet. A droplet containing $12 \mathrm{~mm}$ fluorescein flows through the laser spot and emits fluorescent light which is detected by a photomultiplier tube. This electronic signal triggers an electric pulse which fuses the selected droplet with the continuous aqueous flow. Reproduced with permission from Ref. [119]. b) Fluorescence micrograph droplets, containing bacteria overexpressing $\beta$-galactosidase, in the channel of a microfluidic device. c) Histograms of the fluorescent signals in a mixed emulsion containing droplets of 25 and $100 \mu \mathrm{M}$ sodium fluorescein. The two populations of droplets were clearly separated, with the sorting gate (gray rectangle) selecting only the high-fluorescence droplets. Reproduced with permission from Ref. [118]. error rate of 1 in 100 or 1 in 1000 droplets for droplets sorting rates of 2 or $1 \mathrm{kHz}$, respectively. ${ }^{[118]}$ The fluorescence activated sorting set-up, referred to as FADS (fluorescenceactivated droplet sorting), follows similar work by Fidalgo et al. who combined fluorescence intensity detection with selective "emulsion separation", extracting target droplets into a continuous aqueous stream (Figure 6a). Their system allowed the selection of $30 \mathrm{~nm}$ fluorescein droplets from a stream containing 10 and $30 \mathrm{~nm}$ fluorescein droplets, with less than $1 \%$ false positives. ${ }^{[119]}$

\section{Online Characterization of Reactions in Droplets}

With on-chip control of droplet manipulation becoming more reliable and integrated into more complex devices, there is a strong drive to develop the microdroplets platform as a tool for biological and chemical research. ${ }^{[14]}$ This step requires the ability to handle and chemically analyze thousands of extremely small samples, encapsulated in oil. In the following Sections an overview of the progress in on-chip analytical tools is provided.

\subsection{Fluorescence}

Fluorescence measurements remain the most prevalent and successful method to analyze the contents of droplets. It is important to distinguish the type of information arising from different experimental set-ups. The most widely used way of measuring fluorescence is widefield fluorescence microscopy, requiring only a fluorescence microscope equipped with a sensitive camera to image areas of interest. This technique has been used to measure enzyme kinetics in continuously moving droplets. ${ }^{[9,120]}$ For example, parallel microdroplets technology ${ }^{[121]}$ gives access to fast enzyme characterization $\left(k_{\text {cat }}\right.$ and $K_{\mathrm{M}}$ ). The substrate is diluted on chip through a concentration-gradient device, each flow is merged with the enzyme flow, and droplets are formed simultaneously for each concentration. As droplets travel through their respective channels, fluorescence imaging allows parallel fluorescence measurements over time for each individual reaction. Unfortunately, the droplet frequency is typically much higher than the frame rate of the CCD camera recording. This lack of sensitivity prevents the interrogation of individual droplets and all the kinetics reported are obtained from the average fluorescence intensity of several hundreds of droplets flowing through the detection area during the exposure time.

To interrogate the contents of individual droplets by fluorescence imaging the flow of droplets has to be stopped. For example, insight into blood clotting has been obtained by quantitative analysis of thrombin generation over time as well as a qualitative analysis of formation of fibrin clots in plugs of plasma by combining fluorescence and bright-field microscopy. ${ }^{[122]}$ Various microfluidic microdroplet devices have been developed and coupled with fluorescence imaging to follow the time course of long reactions (several hours) in thousands of individual compartments thereby generating good statistics for population studies. ${ }^{[70,105,123]}$ 
In addition to the ability to follow thousands of single droplets over time, fluorescence imaging has the great advantage to give localization information in a quantitative manner. Therefore, it has been widely used to characterize the interactions of biological samples with the droplet surface, so as to study proteins, ${ }^{[1,73,75]}$ droplet shrinkage, ${ }^{[105]}$ the leaking of droplet content, and communication between droplets. ${ }^{[70]}$ For example, Courtois et al. studied the release of fluorescein derivatives from droplets stored between $6 \mathrm{~h}$ and $18 \mathrm{~h}$ in a reservoir device. Fluorescence imaging offered visualization, localization, and quantification of the fluorescence over time for droplets in heterogeneous emulsions containing both buffer droplets and fluorescein-derivative droplets. This approach enabled to the leaking of fluorescein derivatives to be characterized as a function of the number of buffer droplets surrounding fluorescent droplets. ${ }^{[70]}$

While fluorescence imaging allows the study of the localization of the fluorescence inside droplets, this detection system lacks, in most cases, the high-throughput desired for screening, as well as the possibility to integrate further handling steps for each individual reactor (for example, droplet sorting). For these purposes, laser-induced fluorescence spectroscopy, offering very sensitive and ultra-fast detection has been widely used in various applications, such as cell-based assays, PCR detection, and binding assay. Huebner et al. encapsulated cells into droplets and detected the expression of fluorescent protein in the cells. The confocal laser induced fluorescence detection system resolved fluorescence "events" at $100 \mathrm{kHz}$, and the fluorescence background signal defined the droplet boundaries whereas photon bursts on the top of background were used to identify the number of cells per droplet. ${ }^{[55]}$

Srisa-Art et al. used fluorescence lifetime imaging (FLIM) in droplets to monitor the mixing of two fluorescent dyes with significantly different lifetimes to achieve $5 \mathrm{~ms}$ temporal resolution. By measuring lifetimes at different points along the channel, a 2D image representing the mixing in the droplets can be generated. ${ }^{[124]}$ The same group used fluorescence energy transfer (FRET) to study proteinprotein interactions in droplets. ${ }^{[125]}$ A FRET donor attached to streptavidin and a FRET acceptor attached to a DNA strand complementary to a biotin-modified DNA strand lead to a detectable FRET signal upon hybridization of the DNA pairs. By measuring the FRET efficiency at different points in a delay line, the binding kinetics as well as binding rate constants could be determined. FRET measurements have also been applied to protein-protein interaction studies using an antigen-antibody binding pair labeled with a FRET donor-acceptor pair. ${ }^{[126]}$

\subsection{Raman Spectroscopy}

Raman spectroscopy can provide information on both chemical structure and concentration within microdroplets. It is a non-destructive, label-free detection approach that can be used to track droplet contents in real time. Raman spectroscopy has been used to determine fundamental droplet properties, such as droplet length, by looking at the spectral contributions from the dispersed and continuous phases. ${ }^{[127]}$ It is also possible to follow the mixing of two solutions within the droplets using the spatial resolution afforded by Raman detection. ${ }^{[127,128]}$ Sarrazin, et al. ${ }^{[128]}$ studied mixing within microdroplet reactors in a serpentine chaotic-advection device by tracking the isotopic exchange reaction between $\mathrm{D}_{2} \mathrm{O}$ and $\mathrm{H}_{2} \mathrm{O}$. Averaging over approximately 900 droplets, they mapped the concentration profiles of the starting materials and product (HOD) for this diffusion-limited reaction to determine that the system is well-mixed after $20 \mathrm{~ms}$. In addition to studying the movement of analytes within droplets, Raman spectroscopy provides a tool for reaction optimization in cases where the product is of interest. The UV photopolymerization of methacrylate is important for dental materials, and has been optimized in droplets by varying the methacrylate-based monomer/dimethacrylatecross-linker composition and monitoring conversion using Raman spectroscopy. ${ }^{[129]}$

Surface-enhanced Raman spectroscopy (SERS) makes use of colloids with surface plasmons to amplify the Raman signal. While the addition of these colloids can greatly increase the sensitivity of the measurement, in conventional cuvette measurements and also in continuous-flow cells deposition of the colloids and analyte molecules on the cuvette or channel surfaces can lead to artifacts in the measurements. This so called "memory effect", where sample is detected in a flow cell even after it is no longer introduced, can be eliminated through the use of segmented-flow microfluidics, and delay channels can be used to facilitate interaction between the analyte and the colloids within the droplets. ${ }^{[130]}$ SERS offers great potential for sensitive measurements, and has been used to detect mercury in droplets by following a decrease in SERS signal from rhodamine B adsorbed on Au nanoparticles after displacement by mercury(II) ions. ${ }^{[131]}$

\subsection{Mass Spectrometry and Electrophoresis}

Mass spectrometry (MS) provides a potentially universal label-free method to study chemical and biological reactions, and the technique has been successfully integrated in microfluidic formats. ${ }^{[132-135]}$

The coupling of microdroplets in microfluidics with analytical tools, such as electrophoresis, mass spectrometry or chromatography, is challenging as the continuous (oil) phase strongly interferes with the detection techniques. The coupling of continuous-flow microfluidics and droplet-based microfluidics therefore represents a fundamental step towards the formation of integrated systems that can perform a series of reactions in microdroplets with subsequent electrophoretic or chromatographic separation and mass spectrometric or HPLC analysis of the reaction products after conversion from a droplet-based system into a continuous-flow system. ${ }^{[136]}$ The first steps were reported by Fidalgo et al. ${ }^{[119]}$ and Roman et al. ${ }^{[137]}$ In both cases, a "virtual wall" between a droplet channel with a hydrophobic carrier phase and a continuous aqueous flow was established (see Figure 6 a for the extraction of content from droplets into continuous 
flow). In the work by Roman et al. aqueous droplets in the oil phase come into contact with the virtual wall, resulting in coalescence transfer of the sample to the continuous aqueous phase. Such "injected zones" can subsequently be transferred to a separation channel in which electrophoretic separation occurs.

Fidalgo et al. used pulsed electric fields to drive aqueous droplets in a continuous oil stream towards the virtual wall interface with a co-flowing continuous aqueous stream. The electric fields not only allow droplet manipulation by dielectrophoresis but also lead to electrocoalescence and thus induce emulsion separation. This technique bridges the gap between microdroplets and continuous-flow microfluidics. Recently, the same group reported that this technique can be directly interfaced with electrospray ionization mass spectrometry (ESI-MS) by using polyether ether ketone (PEEK) tubing to connect the outlet of a PDMS chip to a fused-silica MS emitter. ${ }^{[138]}$ Using electric pulses to selectively coalesce droplets with the aqueous stream, the contents of individual droplets were interrogated by MS. As a proof of principle for identifying unknown droplet contents, two kinds of droplets were formed each containing a different peptide (angiotensin or bradykinin) and MS was used to determine which peptide was present in a given droplet. Furthermore, the possibility to combine this technique with fluorescencebased pre-screening was illustrated by producing droplets of angiotensin with and without fluorescent tags. Droplets were selectively chosen for MS analysis based on their fluorescence intensity, a capability that could prove very useful in a variety of high-throughput screening applications. The limitation of these devices was the high limit of detection (ca. $500 \mu \mathrm{M}$ ) owing to the Taylor dispersion of the droplet contents upon fusing with the continuous flow. Kelly and co-workers solved this problem by integrating the electrospray emitter tip into the microfluidic devices, significantly reducing the dispersion in the aqueous channel (Figure 7). These devices were capable of detecting peptide concentrations approximately $1 \mu \mathrm{M}$ extracted from approximately $700 \mathrm{pL}$ droplets with frequencies of $0.1 \mathrm{~Hz}^{[139]}$

While integration of on-chip droplet extraction and ESIMS provides an elegant analysis method in systems where the continuous phase interferes with MS, it also introduces significant dilution of the droplet contents. A very different and potentially more powerful method to record MS spectra from single droplets was introduced by Pei et al. ${ }^{[140]}$ who showed that droplet flows can be directly injected into a mass spectrometer (Figure 7). They generated $10-50 \mathrm{~nL}$ droplets within Teflon tubing, separated by air and a thin layer of fluorinated oil. The tubing was connected to the mass spectrometer by a fused silica nanospray emitter tip. Using this direct, continuous sampling approach, they were able to achieve minimal $(<0.1 \%)$ carry-over between droplets and a detection limit of approximately $1 \mathrm{~nm}$ with leucine-enkephalin samples.

\subsection{Electrochemical Detection}

While less universal than mass spectrometry, electrochemical detection can also be used to gain information on physical and chemical properties of droplets. Electrochemical detection presents an inexpensive alternative to microscope/ fast-camera systems commonly used for monitoring droplet production and has been used to measure droplet length, frequency, and velocity. ${ }^{[141]}$ The technique also provides the opportunity to use opaque chips, expanding the range of materials from which devices for droplet-based microfluidics can be produced.

Additionally, electrochemical detection can be used to analyze the chemical contents of microdroplets. As a proof of principle, quantification of $\mathrm{NaCl}$ concentration, with a $20 \mathrm{um}$ detection limit, has been conducted. ${ }^{[142]}$ Amperometric methods have also been used to study rapid enzyme kinetics. ${ }^{[143]}$ In contrast to fluorescence-based enzyme assays that rely on the use of a fluorogenic substrate, this label-free method can be applied to any reaction involving an electrochemically active reactant or product. Using a simple system involving only a pair of electrodes at a common exit, the conversion of $\mathrm{H}_{2} \mathrm{O}_{2}$ by catalase was monitored to determine $K_{\mathrm{m}}$ and $V_{\text {max }}$. Pneumatic valves were used to sample droplets from a moving stream and control the droplet residence time.

\section{Cells in Droplets}

Droplets can provide a well-defined (potentially sterile) environment into which individual cells can be loaded in a controlled way. The droplet content can be varied systematically when the droplet is created, and modified subsequently by fusion with another droplet. Microdroplets enable the
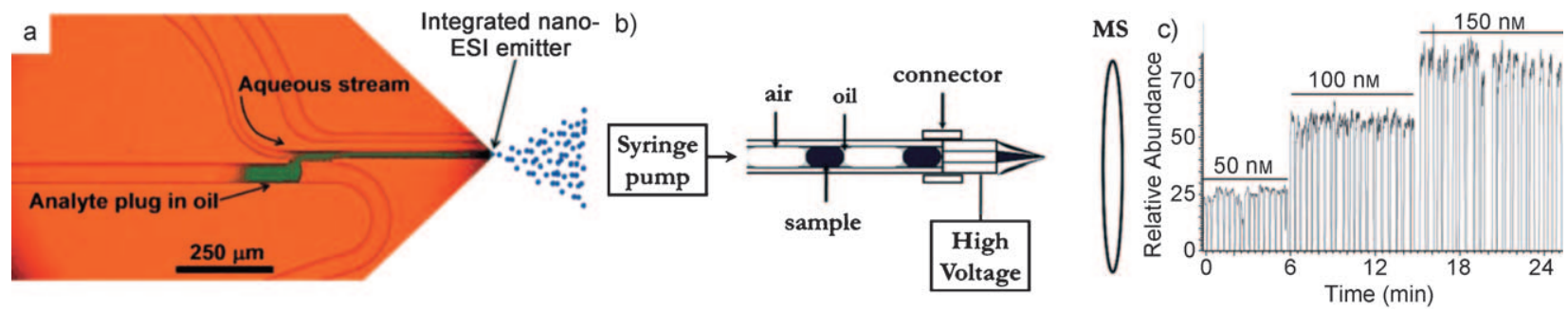

Figure 7. Integration of droplet-based fluidics with mass spectrometry. a) On-chip interface between the aqueous and droplet channels, with the aqueous stream leading to the electrospray emitter. Reproduced with permission from Ref. [139]. b) Overview of scheme for analyzing a train of droplets stored in the Teflon tube. c) Extracted ion current for a series of $50 \mathrm{~nL}$ droplets with increasing concentrations of leucine-enkephalin, dissolved in water with $50 \%$ methanol, $1 \%$ acetic acid. Reproduced with permission from Ref. [140]. 
scale of cell-based assays to be reduced, potentially from $\mu \mathrm{L}$ to $\mathrm{pL}$ volumes, with a concomitant reduction in the use of reagents and cells. In principle it should be possible to carry out assays much faster than in conventional microtitre plates. Most experiments have been reported with bacterial ${ }^{[55,69,144,145]}$ and yeast ${ }^{[106]}$ cells, although there have been some reports using human cells, ${ }^{[60]}$ other mammalian cells, ${ }^{[56]}$ and even organisms such as C. elegans. ${ }^{[60]}$ An integrated cell culture lab-on-a-chip for cultivation of mammalian cells and delivery into microfluidic microdroplets has been described. ${ }^{[146]}$ It has been shown that both suspension and adherent cells can be maintained in microdroplets for over nine days, and that the cells can be recovered and recultivated. The use of gas permeable perfluorocarbon carrier oils, allows the cells to be kept alive for several days and cell cultures in droplet flows have comparable viability to cultures in flasks. ${ }^{[60,145]}$

A general method for a single-cell-based assay in microdroplets has been described by $\mathrm{He}$ et al. who compartmentalized cells prior to lysis by rapid laser photolysis to gain access to over-expressed enzymes. Selected single cells expressing $\beta$-galactosidase were mixed in droplets with the fluorogenic substrate. No reaction occurred until the cell content was released inside the droplet. The cell lysate was confined inside the droplet where the enzymatic reaction took place. ${ }^{[49]}$ Single-cell-based assays of over-expressed $\beta$-galactosidase have also been realized by permeabilizing the cell membrane to introduce the substrate. ${ }^{[123]}$

If an enzyme is expressed in the periplasm, the need for cell lysis or permeabilization can be eliminated. Cell-based assays for periplasmic-expressed enzymes have been carried out inside picoliter microdroplets that contain E. coli cells over-expressing the enzyme, alkaline phosphatase (AP). Once the enzyme was transported to the periplasm it hydrolyzed the (non-cell permeable) substrate fluorescein phosphate, releasing fluorescein into the droplet. ${ }^{[144]}$ The catalytic turnover of the substrate was measured in individual droplets by monitoring the fluorescence at several times in the device. Similar kinetics were detected to those obtained in assays carried out in bulk solution. A multilayer microfluidic device was recently used to quantitatively measure the kinetics of protein expression and enzymatic activity in individual cells compartmentalized in droplets (Figure 8). As the volume of the droplets in such devices can be kept constant for the duration of the experiments $(>5 \mathrm{~h})$, the fluorescence intensity measured in each droplet can be compared quantitatively. Cells harboring a plasmid for the co-expression of AP and red fluorescent protein (mRFP1) were encapsulated in microdroplets with a fluorogenic substrate and an inducer of protein expression. The fluores- cence arising from mRFP1 expression remained localized in the cells, while the fluorescent product of the alkaline phosphatase reaction spread throughout the droplets. In this case, the mRFP1 intensity serves as an internal standard to calibrate the activity and amount of enzyme expressed in each cell. The ability to simultaneously monitor these properties provides an analytical tool for the assessment of members of a library in a directed evolution experiment or allows interrogation of the heterogeneity of cells generated from an identically prepared ensemble. ${ }^{[147]}$

In a further extension of enzymatic assays in droplets, enzymatic amplification of low-abundance cell-surface biomarkers has been reported, which is effectively a miniaturized ELISA (enzyme-linked immunosorbent assay). ${ }^{[148]}$ Cells bearing specific biomarkers were labeled with an antibody linked to $\beta$-galactosidase and were co-encapsulated with a fluorogenic substrate. The increase in fluorescence was measured by laser detection after incubation offline and reinjection of the droplets for detection. The droplet compartmentalization is exploited to study cell populations by encoding the droplets with a color code before enzymatic amplification. In comparison to standard FACS methods, in which the antibody is labeled with a dye rather than an enzyme that allows for turnover of many dye molecules, the droplet-based enzymatic amplification approach allowed for four- to seven-fold more cells containing biomarkers to be discriminated from a population of cells. ${ }^{[148]}$

The "dropspot" devices (Figure 5) have been used to study the growth of yeast cells. A marked variation in doubling time was noted, with the doubling time being slower in droplets initially containing more cells. This observed variation may be attributed to cell-cycle asynchrony as well as a consequence of the high cell density of an encapsulated cell: the volume per cell of even a single cell in a drop of $40 \mu \mathrm{m}$ diameter is equivalent to $10^{8}$ cells $\mathrm{mL}^{-1}$, which is near the

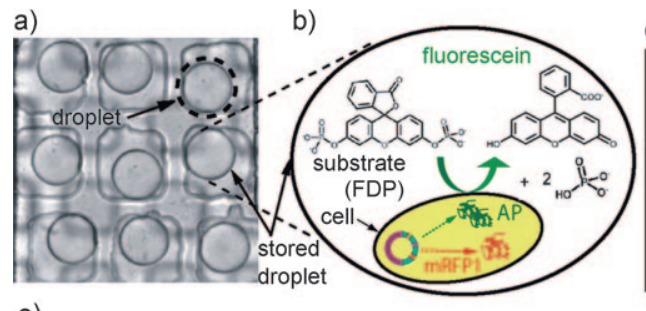

e)

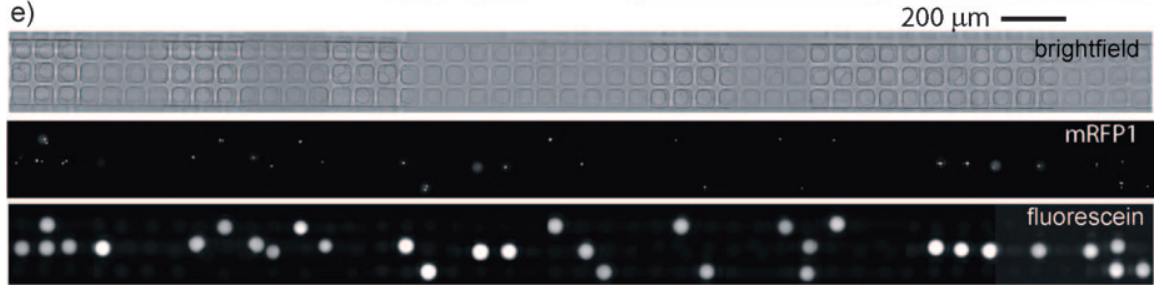

Figure 8. a) A bright-field image of droplets stored in square wells. b) Compartmentalized cells co-express the two target proteins, AP and mRFP1, under the control of two identical promoters. AP hydrolyzes the substrate (FDP) to yield fluorescent products. c) Fluorescence image showing mRFP1 expression. The bright spots are cells expressing mRFP1 and encapsulated in microdroplets. d) Fluorescence image showing the accumulation of fluorescent product uniformly distributed within the droplets. e) Stitched micrographs showing, from top to bottom, droplets in the storage area in bright-field, red, and green fluorescent images, respectively, taken $20 \mathrm{~h}$ after droplet formation. Reproduced with permission from Ref. [147]. 
density of a saturated culture of yeast cells. ${ }^{[106]}$ Studies on stationary droplets containing single cells highlight the potential of the microdroplets platform for future studies into stochastic phenotypic variations within populations of genetically identical cells. A new tool allowing the sizing of small particles in droplets opens up the possibility to study sub-cellular components, such as synaptic vesicles, in droplets. $^{[149]}$

The increased cell density achievable in small volumes (not necessarily droplets in an oil carrier phase) has been applied to study quorum sensing or cell signaling amongst bacteria. ${ }^{[69,150]}$ Quorum sensing is involved in many processes including sporulation, biofilm formation, antibiotic production, and bioluminescence and involves release of chemical signals when the bacteria reach a certain cell density. This phenomenon has previously been studied in bulk solution, but compartmentalization in microdroplets provides a completely different perspective. A single cell in a $10 \mu \mathrm{m}$ diameter droplet (volume $500 \mathrm{fL}$ ) corresponds to a cell density of $2 \times$ $10^{9}$ cells per $\mathrm{mL}$, which is over 20-times the cell density required for induction of quorum sensing. Consequently by using small droplets it is possible to study high cell densities using one or a few cells. A recent study used $100 \mathrm{fL}$ droplets immobilized in wells to entrap $P$. aeruginosa cells containing a fluorescent reporter under the control of the quorum-sensingcontrolled lasB gene. Droplets containing as few as one or two cells exhibited quorum sensing, but with considerable heterogeneity, presumably because of stochastic effects. ${ }^{[151]}$

On-chip lysis of cells in droplets provides a means to access the cell contents, but it is also a potential route to introduce material into cells. In a recent report, Zhan et al. ${ }^{[152]}$ demonstrated a simple microfluidic device to encapsulate and electroporate cells in aqueous droplets. The transformation occurred when the cell-containing droplets (in oil) flowed through a pair of micro-electrodes between which a constant voltage was established. The potential of the technique was demonstrated by delivering enhanced green fluorescent protein (EGFP) plasmid into Chinese hamster ovary $(\mathrm{CHO})$ cells. Yeast cells encapsulated in droplets have also been electroporated using high voltages to facilitate the introduction of small molecules into the cells. ${ }^{[42]}$ Another promising method for transfection of cells is the co-compartmentalization of cells and cationic lipid-DNA complexes. The formation of non-viral vectors in microdroplets allows far greater control over the ratio and polydispersity of the vectors and more reproducible gene delivery. ${ }^{[153]}$

With the ability to electroporate, interrogate, and manipulate single cells within droplets, the need for a means of droplet archiving to make use of cells in droplets over longer periods of time has arisen. Freezing droplets containing single cells may provide a useful link between compartmentalization and long-term storage. To cool streams of moving droplets, thermoelectric coolers have been used to locally cool microfluidic devices, causing the aqueous droplets within a targeted region to freeze. Auspiciously, a low-freezing-point continuous phase allows the frozen droplets to keep moving, so that the droplets and their frozen cargo can be collected. Using cryoprotectants, mouse B lymphocytes contained within the frozen droplets were still viable after one week of storage. ${ }^{[154]}$

\section{G. In Vitro Transcription/Translation}

The resolution of a population into individuals that can be encapsulated in microdroplets can be the basis for the construction of a library. Droplets are emerging as a particularly useful tool in this respect, because the compartmentalization they provide mimics the effect of the cell boundary. The droplet links the genotype (DNA or RNA) to the phenotype (i.e. an observable trait, such as binding or catalytic activity), providing an opportunity to artificially "evolve" proteins with a desired function and maintain evidence of this function in a confined space similar to a cell. In a molecular-evolution experiment based on this principle, droplets contain a single member of a nucleic acid library that is transcribed and translated, often by commercially available in vitro transcription/translation (IVTT) extracts (e.g. from E. coli, wheat germ, or rabbit reticulocytes). Such a format is entirely in vitro and therefore advantageous over other evolution experiments that involve organisms: expression of proteins that are toxic to the host cells are possible; non-natural cofactors and non-natural amino acids can be included in selections; the selection environment can include co-solvents or extremes of $\mathrm{pH}$ value and temperature. Finally the selection pressure cannot easily be circumvented as only a minimal number of other processes occur in the controlled droplet environment. The most straightforward format is to compartmentalize one gene copy into each droplet, creating "monoclonal" cell-like evolutionary units.

The high-throughput formation of monodisperse subpicoliter size microreactors for in vitro expression of green fluorescent protein (GFP) was first reported by Dittrich et al. ${ }^{[155]}$ This system has been extended by Courtois et al. who developed a reservoir device to store up to $10^{6}$ subpicoliter droplets for several hours and monitored the in vitro expression of GFP therein. High yields of GFP were obtained, making it possible to perform protein expression from single copies of the DNA template, creating "monoclonal droplets" in which genotype and phenotype are combined in one emulsion compartment. ${ }^{[22]}$ The availability of monoclonal droplets containing a single DNA template is a major step towards future in vitro directed-evolution experiments.

The in vitro expression and simultaneous detection of an enzyme has also been achieved. Several hundred copies of plasmid DNA encoding $\beta$-galactosidase were co-compartmentalized with IVTT extract and a fluorogenic substrate, and the enzymatic activity was detected by fluorescence imaging. ${ }^{[74]}$ It is also possible to amplify the DNA prior to transcription. Using multiple microfluidic chips along with droplet collection/re-injection it is possible to isolate each biochemical step, while integrating DNA amplification with IVTT ${ }^{[156]}$ Droplets containing ingredients for isothermal PCR by "hyperbranched rolling circle amplification" (HRCA) have been incubated off-chip and then fused with droplets containing the IVTT mixture to produce $\beta$-galactosidase. The droplets were then re-injected into an analysis chip to quantify enzyme activity using a fluorogenic assay. ${ }^{[156]}$ In many cases, however, the optimal conditions for IVTT and the subsequent enzymatic assay differ; for example, a component 
for the enzyme assay may inhibit the IVTT and vice versa or it may be necessary to run the two processes at different $\mathrm{pH}$ values. To overcome this limitation, the processes can be separated by first performing IVTT in droplets and fusing the droplets, after translation, with larger droplets containing the components for an enzymatic assay. ${ }^{[88]}$

\section{Polymerase Chain Reaction (PCR) in Droplets}

Modern molecular biology is unthinkable without the polymerase chain reaction (PCR). Performing this key technique in droplets supplements the repertoire of biological operations in droplets, and takes advantage of a number of typical features of this format. Miniaturization allows operation with small volumes and high-throughput. Fast heat transfer at the microscale enables reduced reaction times. In contrast to conventional microfluidics, the droplet compartment protects polymerases and template DNA from interactions with the channel walls, thus preventing inactivation of polymerase and cross contamination between samples. ${ }^{[157]}$

Droplets containing only a single DNA molecule (or several identical copies) are referred to as "monoclonal", in analogy to a cellular clone. The isolation of each template into a different droplet avoids competition and recombination between multiple amplicons. Monoclonality ensures that the amplification efficiency of each amplicon is very similar and avoids artifact recombination products. As a consequence the products of compartmentalized PCR reflect the original composition of complex mixtures, such as genomic libraries with varying template lengths or $\mathrm{G} / \mathrm{C}$ content, more closely than conventional PCR. ${ }^{[158]}$ One way to maintain monoclonality after the droplets have been broken up, is to capture amplified DNA on a microbead. By applying these principles in vitro clonal arrays are generated in which thousands of copies of DNA identical in sequence to the original are attached to a bead. ${ }^{[159,160]}$ These beads are used for highthroughput second-generation sequencing ${ }^{[16,161]}$ for quantification of rare events in large populations, such as the detection of mutated cancer cells, ${ }^{[159,162,163]}$ and high-throughput screening of transcription-factor targets. ${ }^{[164]}$

Monoclonal droplets also offer a format for detection and quantification of very small amounts of nucleic acids, that are encountered, for example, in medical diagnostics, such as viral or pathogen contamination. In "digital PCR" the fraction of droplets in which amplification occurs (corresponding to the presence of template DNA in these droplets) compared to the total number of droplets correlates to the amount of DNA in a sample by Poisson statistics. The readout of digital PCR is simply whether amplification has occurred in a droplet or not. ${ }^{[165]}$ These linear digital signals are more reliable than data from conventional DNA quantification in which the exponential DNA amplification has to be monitored and fitted. The high-throughput of microfluidic droplets is ideally suited to reach low detection limits, with the minimum detectable concentration decreasing with the number of compartments.

The original emulsion PCRs (ePCRs) were performed in bulk emulsions. ${ }^{[158]}$ The first microfluidic setups for ePCR used large $(n L-\mu L)$ droplets. ${ }^{[66-169]}$ Viovy and co-workers investigated similar emulsion PCR-type reactions in tubing, with large $(\mu \mathrm{L})$ droplets, consisting of a long coil flowing across hot and cold sections in a copper cylinder. ${ }^{[170,171]}$ Now, devices are available that integrate microfluidic control with picoliter droplet handling, dramatically increasing the potential throughput. Initially, on-chip microfluidic set-ups for PCR involved temperature cycling of the entire chip. ${ }^{[172,173]}$ The time required to bring droplets to a desired temperature can be reduced when the temperature is maintained locally on a chip and the droplet passes through individual temperature zones, either in serpentine ${ }^{[174]}$ or radial designs (Figure 9). ${ }^{[58]}$ As in conventional PCR, precise temperature control is important for the efficiency of amplification in microfluidic droplets. The temperature-dependence of fluorescence lifetimes of dyes has been used to guide adjustment of the temperature inside droplet. ${ }^{[5]}$ To circumvent the problem of temperature control on the device, it is also possible to form monodisperse droplets with a microfluidic device, collect them in a vial, and then perform the PCR in a commercial bench-top thermocycler. ${ }^{[163,175]}$ If necessary, droplets can be

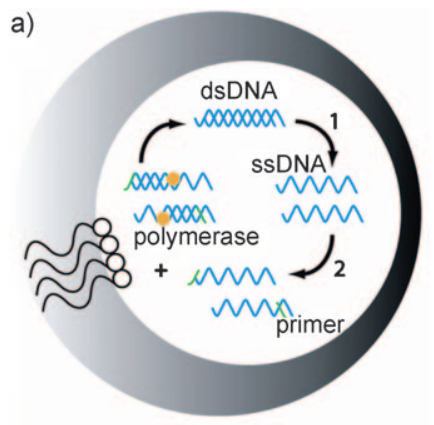

b)

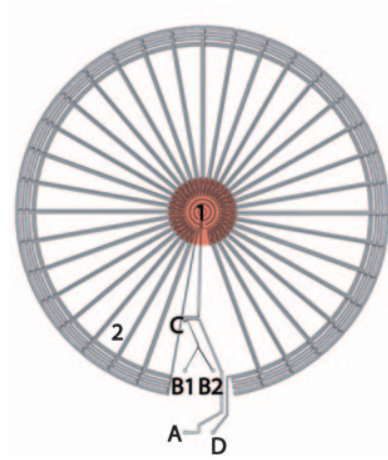

c)

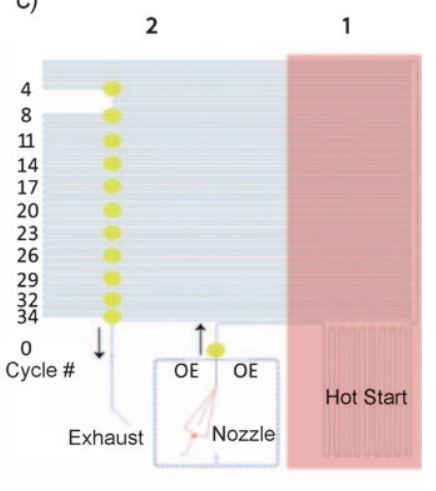

Figure 9. Continuous-flow PCR in microfluidic droplets for highthroughput applications. a) General overview for a two-temperature PCR method for amplifying double-stranded DNA. b),c) Two designs for continuous-flow PCR in which droplets traverse alternating temperature zones to achieve the thermal cycling: b) Radial design: the droplets pass through the inner circles in the hot zone for initial denaturation and travel on to the periphery for primer annealing and template extension. The droplets then return to the center, where a new cycle begins, and after 34 cycles exit the device. Reproduced with permission from Ref. [58]. c) Serpentine design: droplets pass 34 times through static thermal zones of denaturation and of primer annealing and template extension on alternate sides of the chip. At the yellow regions progress of the PCR reaction is monitored by fluorescence. Reproduced with permission from Ref. [174]. 
re-injected into a microfluidic device for further manipulations, such as merging. Such a setup is used for targeted sequencing of genomic regions of interest. ${ }^{[175]}$ In this case, the lack of PCR bias in droplets provides uniformity of the amplified DNA, thus reducing the number of necessary repeats in subsequent (re-)sequencing. It is also possible to avoid completely temperature cycling using an isothermal amplification system as an alternative to PCR. ${ }^{[156]}$

\section{Small-Molecule Synthesis in Droplets}

The combination of on-chip synthesis and screening is desirable as it provides a fluidic interface between the stored compound libraries in use in the pharmaceutical industry and cell-based screening. Recently, Mugherli et al. published the in-droplet synthesis and screening of enzyme inhibitors, though on a surface-tension microarray rather than within microfluidic channels. ${ }^{[176]}$ Reagents dissolved in a DMSO/ glycerol mixture (to avoid evaporation) were spotted onto glass slides modified with 800 hydrophilic spots. Subsequently, solutions of enzyme and substrate were spotted over the initial droplets, thereby diluting the residual starting compounds and minimizing the background inhibitor effect. The presence of inhibitor in the droplets was assayed on the same chip by monitoring the increase in fluorescence intensity. This work demonstrates the potential of a dropletbased synthetic platform for small-molecule synthesis, where many of the above operations (droplet formation, fusion, dilution, fluorescence intensity measurements) have already been demonstrated. The synthesis of small molecules in droplets in microfluidic channels is challenging, but provides interesting opportunities, as will be reviewed below.

Droplets provide an ideal platform for high-throughput screening and have been used to screen reaction conditions for the selective hydrolysis of ouabain hexaacetate, derivatives of which are useful for neuron studies. Consuming only $20 \mu \mathrm{g}$ of substrate, over 40 different reaction conditions were tested, and the results evaluated using MALDI-MS. ${ }^{[177]}$ Another important advantage arising from the discrete nature of microdroplets is the ability to perform precipitateforming reactions without clogging the microfluidic channel. This feature was first demonstrated in the synthesis of indigo and for imine and amide formation reactions. The precipitate remained in the dispersed phase, whereas the continuous phase preferentially wet the channel walls, preventing the solid product from clogging the channels. ${ }^{[178]}$

The high surface-to-volume ratio inherent to the dimensions of the droplets and the internal flow circulations in droplets in microfluidic channels can significantly enhance mass transfer between the dispersed and continuous phases. ${ }^{[28,179,180]}$ Several groups have capitalized on this to facilitate phase-transfer reactions. Onal et al. reported a triphasic regioselective hydrogenation of $\alpha, \beta$-unsaturated aldehydes using organic reagents in droplets and hydrogen gas bubbles dispersed in an aqueous catalytic stream. In droplet-based microfluidics, internal flow circulations (Taylor flow) arise as a result of the shear forces at the channel walls. These flow patterns can enhance mass transfer at the liquid- liquid interface. A dramatic increase in reaction rate was obtained with a decrease in channel diameter since Taylor flows become more pronounced with decreasing channel dimensions. Furthermore, increasing the aqueous flow rate led to an increase in conversion, which was attributed to an increase in the Reynold's number which influences the masstransport coefficient of the system. ${ }^{[181]}$

Rapid reagent mixing brought about by internal flow circulations also lead to a significant rate enhancement for the hydrolysis of $p$-nitrophenyl acetate as well as for a tandem diazotation/Heck reaction in segmented flow compared to the same reaction in a laminar flow. ${ }^{[182,183]}$ A similar trend was observed in the biphasic nitration of aromatics. ${ }^{[184]}$ In addition to providing well-controlled liquid-liquid interfaces for the phase-transfer reaction, the microreactor environment facilitated the fast heat transfer crucial to investigating this exothermic reaction.

In addition to facilitating phase transfer of stoichiometric reagents, droplet-based microfluidics also provides a platform for biphasic catalytic reactions. Drawing on advances in fluorous biphasic catalysis, Theberge et al. recently described a system comprising a catalytically active fluorous continuous phase and an aqueous dispersed phase containing Suzuki cross-coupling reagents (Figure 10). ${ }^{[185]}$ To solubilize the palladium catalyst in the fluorous phase and to position the catalyst at the droplet interface, an amphiphilic ligand containing a fluorinated tail and a hydrophilic guanidine head was introduced. A range of Suzuki cross-coupling products was obtained in good yield, and the catalytically active fluorous phase could be recycled in a closed-loop, uninterrupted fashion by pooling the droplets at the end of the reaction channel.

Reaction scale-up poses a major challenge in conventional reactors, where changing the scale of the reaction requires

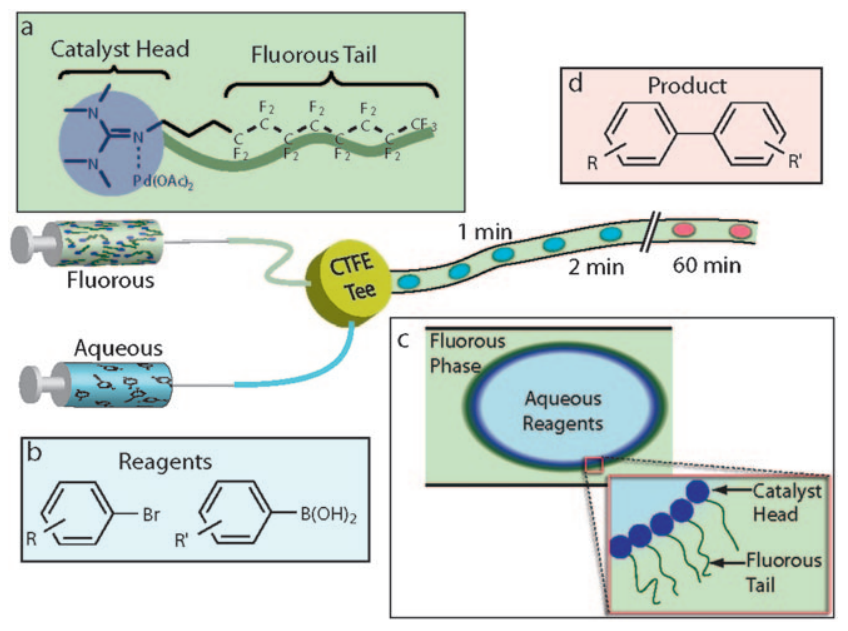

Figure 10. Representation of microdroplets with catalytically active surfaces. Fluorous-tagged palladium catalyst (a) and aqueous reagents (b) are pumped into the T-junction, forming monodisperse aqueous droplets surrounded by the fluorous continuous phase. Product is formed as the droplets flow through the channel $(c, d)$. The reaction time is linearly proportional to distance along the tubing and can be controlled by varying the flow rates. Reproduced with permission from Ref. [185]. 
developing new conditions to accommodate changes in mixing, solvent volume, and other scale-related factors. Wheeler et al. demonstrated that droplet flow chemistry allows an alternative method of scale-up: reactions can be scaled up by increasing the droplet size within a certain regime or by simply increasing the number of droplets. These principles were demonstrated with $\alpha$-diazo- $\beta$-keto ester synthesis and a nucleophilic aromatic substitution reaction, albeit with far larger droplet volumes $(>100 \mu \mathrm{L})$ than used in nonindustrial applications of droplet-based synthesis. ${ }^{[186]}$ Using perfluoromethyldecalin (PFMD), a low-microwave absorber, as a carrier phase, the group also showed that microwave technology can be applied to Suzuki-Miyaura cross-coupling and nucleophilic substitution reactions in droplets. ${ }^{[187]}$

\section{Polymer and Gel Particles}

The monodisperse nature of droplets produced in microfluidics channels can provide a unique reaction environment for the formation of particles, gel beads, and capsules. A number of excellent recent Reviews and research papers have given an extensive overview of progress in polymer-particle production, ${ }^{[33,188-190]}$ and the formation of hydro- and microgel particles and capsules. ${ }^{[191-193]}$ Microdroplets can also be used to form hierarchically structured materials, as was demonstrated in the formation of inverse-opaline photonic beads by colloidal crystallization in droplet templates (Figure 11). ${ }^{[194,195]}$ First, an aqueous suspension containing monodisperse polystyrene spheres and ultrafine silica particles was broken into droplets by an oil carrier flow in a microfluidic device. Subsequently, the droplets were collected and during the evaporation of water in the droplets, the polystyrene spheres packed into ordered lattices, and the
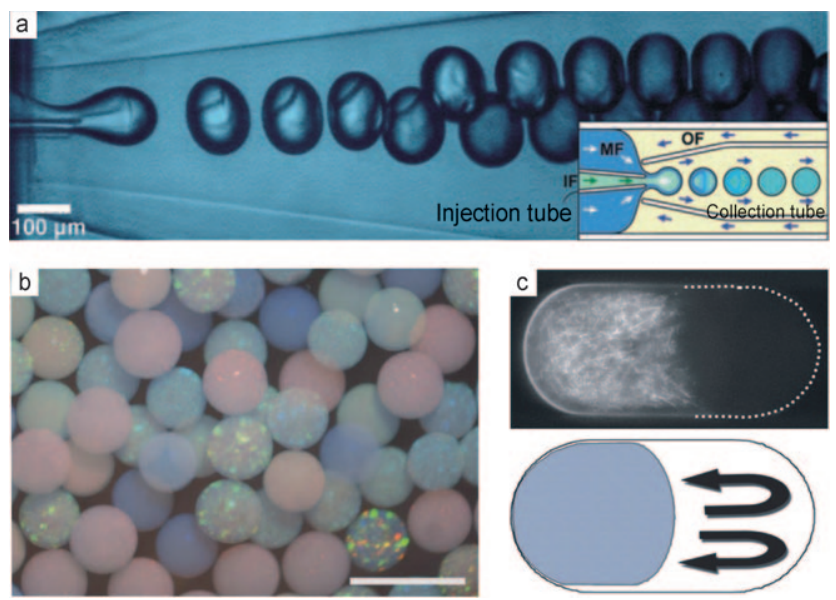

Figure 11. a) Drop formation of pre-microgel drops in a capillary microfluidic device. The inset shows the device geometry. The outer fluid (OF) is silicon oil, the middle fluid (MF) is an aqueous solution containing monomer and cross-linker, and the inner fluid (IF) contains the initiator. Reproduced with permission from Ref. [207] b) Image of the seven different types of inverse-opaline photonic beads in water. Reproduced with permission from Ref. [194]. c) Compression of fibrin networks by flow fields inside droplets. Reproduced with permission from Ref. [228]. ultrafine silica particles infiltrated into the interstitial sites between the spheres. The resulting beads can be used for label-free detection of biomarkers. ${ }^{[196]}$ It is clear that dropletbased fluidics are an extremely useful platform for producing (small volumes) of gel particles with sizes ranging from several tens to several hundreds of microns, a range of pore sizes, responsive properties, and varied compositions, thereby opening up applications in drug delivery, cosmetics, sensors, and biomedical devices. In the following sections only a brief conceptual overview of the applications will be provided.

\subsection{Particle Polymerization}

Polymerization of droplets is usually performed upon incorporating a curing agent directly into the droplet volume ${ }^{[43]}$ or by delivery from the continuous phase. ${ }^{[197]}$ The use of photoinitiators and UV curing ${ }^{[198]}$ allows precise control over the on-chip location where polymerization takes place, which reduces the overall residence time of the particles in the microfluidic chip. The channel geometry can be utilized to fabricate non-spherical beads or rod-shaped composites, ${ }^{[43,199,200]}$ whereas multiple emulsions can be exploited to form Janus-type particles. ${ }^{[201]}$ A rich range of morphologies, including Janus-type, arises form the internal phase separation of polymer solutions inside microdroplets. ${ }^{[202]}$ The introduction of small gaseous droplets into the droplet volume offers a way to produce porous microparticles. ${ }^{[203]}$ One of the obvious applications of monodisperse polymer particles of controlled size and shape is in the area of drug delivery. Drug compounds can be loaded into the particles during the polymerization step. The monodisperse nature of the carrier particles influences the release profile of the drugs from these particles. ${ }^{[204]}$ Hollow polymer particles (capsules) have been produced in several ways. Interfacial polymerization, where activated initiators diffuse to the interface between the continuous phase and the aqueous droplets and initiate polymerization, ${ }^{[205]}$ is a straightforward method compatible with a wide range of polymers; alternatively, block copolymers have been assembled at the oilwater interface to form nanoporous surface patterns. ${ }^{[06]}$ Double emulsions (Figure 11) consisting of water/oil/water layers lead to polymer shells when the oil interlayer is polymerized, for example, by the addition of an initiator or curing agent to the inner fluid ${ }^{[207]}$ or by UV-curing of the middle phase. ${ }^{[208]}$ An additional advantage is that the shell thicknesses can be varied by changing the flow rates of the inner or middle phases, and the cores can be placed off-center with respect to the shell by varying the shell-phase viscosity. ${ }^{[209]}$ Solvent evaporation of the oil phase has been used to fabricate nanoparticle colloidosomes. ${ }^{[210]}$ The use of a fluidics platform not only guarantees monodipsersity and control over shape but the laminar flow regime can also be used to generate particles composed of spatially distinct regions of polymers by merging two or three parallel co-flowing immiscible polymer streams. Subsequent UV polymerization of droplets produces bi- or multiphasic particles. ${ }^{[211]}$ If only one of the two phases is polymerizable, convex-concave structured particles can be fabricated. ${ }^{[212,213]}$ Induced phase 
separation of polymers in droplets leads to the formation of biphasic particles with a range in internal structures. ${ }^{[192,214]}$

\subsection{Gel Formation in Droplets}

The versatility of producing gels in droplets was demonstrated several years ago in seminal work by Weitz and coworkers, where acrylamide was polymerized with a range of co-monomers and cross-linkers in a double emulsion, with redox initiators in the inner fluid phase. ${ }^{[207]}$ There is an interest in monodisperse gel particles for cell-growth applications or as "suspension arrays" for conserved DNA harvested from colonies growing in beads. ${ }^{[215]}$ Although these experiments did not take place in a droplets platform they illustrate the potential of this technology. Monodisperse microgel particles composed of biological or biocompatible polymers ${ }^{[216-218]}$ can be obtained by chemical gelation, in a similar manner to producing other polymeric particles. ${ }^{[219,220]}$ In the case of temperature-dependent hydrogel components such as agarose, gel particles are formed by simple changes in temperature. ${ }^{[4]}$ Several reports have demonstrated the formation of particles composed of alginate, ${ }^{[221]}$ where gelation is dependent on divalent cations as cross-linking agents and occurs at very high rates. Gel formation can be avoided by separating laminar co-flowing sodium alginate and $\mathrm{CaCl}_{2}$ solutions with a water stream before droplet formation; when the contents are mixed inside the droplets, gelation occurs very rapidly. ${ }^{[199]}$ Alternatively, mixing the two fluids directly prior to droplet formation also leads to gel particles. ${ }^{[205]}$ Gelation induced by droplet-droplet fusion has the advantage that the gel formation cannot occur outside droplets, which avoids problems with channel clogging. ${ }^{[22]}$ A third route for controlling alginate gelation is the delivery of calcium ions from the oil phase, ${ }^{[207]}$ or by the addition of insoluble $\mathrm{CaCO}_{3}$ or $\mathrm{BaCO}_{3}$, co-compartmentalized with alginate containing droplets. The carbonates dissolve upon acidification of the emulsion droplets by diffusion of acetic acid from the oil phase. ${ }^{[22,224]}$ Alginate gel droplets provide a suitable environment for the encapsulation of cells. ${ }^{[225,226]}$ Supramolecular hydrogel microspheres are hydrogel particles formed by the self-assembly of hydrogelators in water, and Shen and co-workers recently demonstrated how aqueous droplets gelated when gradually cooled down from $70^{\circ} \mathrm{C}$ at the droplet formation point, to below $64^{\circ} \mathrm{C}$ downstream in the device. ${ }^{[227]}$

The microfluidics platform has been imaginatively used to provide information on the mechanical properties of gels. ${ }^{[228]}$ Fibrin networks formed in droplets by the thrombin-catalyzed cleavage of fibrinogen were mechanically deformed by flow fields inside the droplets when flowing through narrow channels. The deformation was investigated both during network formation and after maturation (Figure 11). The rate of deformation can easily be controlled and a semiquantitative estimate of the Young's modulus of the network was reported (50-900 $\mathrm{Pa}$ range). This work shows that microdroplets provide not only an ideal tool to manipulate small volumes of reagents, but also have the potential to be used both in the synthesis and mechanical characterization of new, soft materials.

\section{Conclusion and Outlook}

Some 50 years after Lederberg's visionary experiments in polydisperse droplets sprayed onto glass slides, microdroplets in microfluidics has become a fast moving research area that is rapidly being established as a powerful tool for complex chemical and biological experiments. Crucial to this progress has been the development of simple modules for the manipulation of droplets in the past 10 years. Monodisperse droplets can now be generated at tens of $\mathrm{kHz}$ and manipulated on-chip to more or less mirror the operations (including heating, cooling, fusing, mixing, storing, sorting, etc.) essential for carrying out experiments in bulk. In the short term, improvements will arise from the seamless integration of the different modules into single devices, the development of superior surfactants that guarantee droplet integrity under demanding conditions, and the coupling of the microdroplets platform with a wider range of analytical tools. With respect to the latter, NMR spectroscopy is a notable absence from the range of characterization methods that has been explored to study the contents of droplets.

The technological breakthroughs of the last decade have enabled the design of experiments that start to exploit the key characteristics of microdroplets. Compartmentalization is clearly a powerful concept for isolating and studying single cells and their environments. Droplets are monodisperse, can be formed and analyzed at sufficiently large numbers, and manipulated efficiently while containing the small amounts of cellular material uncontaminated within those droplets. Integrated devices coupled to highly sensitive, ideally labelfree detection methods, provide a new tool for exploring single-cell genomics, proteomics, and metabolomics.

On the other side of the natural sciences spectrum, droplets also provide a platform for fundamental studies on reactions in confined spaces, near and across interfaces, and in highly concentrated solutions. As such, the droplets would serve as a model system that mimics some of the essential features of the chemical environment in living cells. A better understanding of how enzymatic reactions are influenced by confinement, crowding, and the presence of interfaces will not only yield a further insight in biological systems, but will also guide the development of new chemical reactions.

We are most grateful to our co-workers for their enthusiastic contributions and Luis M. Fidalgo for providing the table of contents picture. Our work is supported by the European Union (EC Framework 6 Research Project MiFem) and the RCUK Basic Technology Programme.

Received: November 25, 2009

Published online: June 22, 2010

[1] J. Lederberg, J. Bacteriol. 1954, 68, 258.

[2] P. de Fonbrune, Technique de micromanipulation, Masson, Paris, 1949.

[3] G. J. V. Nossal, J. Lederberg, Nature 1958, 181, 1419.

[4] C. Viret, W. Gurr, J. Immunol. 2009, 182, 1229.

[5] B. Rotman, Proc. Natl. Acad. Sci. USA 1961, 47, 1981.

[6] S. Y. Teh, R. Lin, L. H. Hung, A. P. Lee, Lab Chip 2008, 8, 198. 
[7] M. Abdelgawad, A. R. Wheeler, Adv. Mater. 2009, 21, 920.

[8] M. G. Pollack, R. B. Fair, A. D. Shenderov, Appl. Phys. Lett. 2000, 77, 1725 .

[9] H. Song, R. F. Ismagilov, J. Am. Chem. Soc. 2003, 125, 14613.

[10] H. Song, J. D. Tice, R. F. Ismagilov, Angew. Chem. 2003, 115, 792; Angew. Chem. Int. Ed. 2003, 42, 768.

[11] J. D. Tice, H. Song, A. D. Lyon, R. F. Ismagilov, Langmuir 2003 , 19, 9127.

[12] H. Song, D. L. Chen, R. F. Ismagilov, Angew. Chem. 2006, 118 , 7494; Angew. Chem. Int. Ed. 2006, 45, 7336.

[13] A. Huebner, S. Sharma, M. Srisa-Art, F. Hollfelder, J. B. Edel, A. J. Demello, Lab Chip 2008, 8, 1244.

[14] D. T. Chiu, R. M. Lorenz, G. D. M. Jeffries, Anal. Chem. 2009 $81,5111$.

[15] M. Margulies, M. Egholm, W. E. Altman, S. Attiya, J. S. Bader, L. A. Bemben, J. Berka, M. S. Braverman, Y. J. Chen, Z. T. Chen, S. B. Dewell, L. Du, J. M. Fierro, X. V. Gomes, B. C. Godwin, W. He, S. Helgesen, C. H. Ho, G. P. Irzyk, S. C. Jando, M. L. I. Alenquer, T. P. Jarvie, K. B. Jirage, J. B. Kim, J. R. Knight, J. R. Lanza, J. H. Leamon, S. M. Lefkowitz, M. Lei, J. Li, K. L. Lohman, H. Lu, V. B. Makhijani, K. E. McDade, M. P. McKenna, E. W. Myers, E. Nickerson, J. R. Nobile, R. Plant, B. P. Puc, M. T. Ronan, G. T. Roth, G. J. Sarkis, J. F. Simons, J. W. Simpson, M. Srinivasan, K. R. Tartaro, A. Tomasz, K. A. Vogt, G. A. Volkmer, S. H. Wang, Y. Wang, M. P. Weiner, P. G. $\mathrm{Yu}$, R. F. Begley, J. M. Rothberg, Nature 2005, 437, 376.

[16] E. R. Mardis, Trends Genet. 2008, 24, 133.

[17] D. S. Tawfik, A. D. Griffiths, Nat. Biotechnol. 1998, 16, 652.

[18] E. Mastrobattista, V. Taly, E. Chanudet, P. Treacy, B. T. Kelly, A. D. Griffiths, Chem. Biol. 2005, 12, 1291.

[19] J. J. Agresti, B. T. Kelly, A. Jäschke, A. D. Griffiths, Proc. Natl. Acad. Sci. USA 2005, 102, 16170.

[20] M. d'Abbadie, M. Hofreiter, A. Vaisman, D. Loakes, D. Gasparutto, J. Cadet, R. Woodgate, S. Paabo, P. Holliger, Nat. Biotechnol. 2007, 25, 939.

[21] F. J. Ghadessy, N. Ramsay, F. Boudsocq, D. Loakes, A. Brown, S. Iwai, A. Vaisman, R. Woodgate, P. Holliger, Nat. Biotechnol. 2004, 22, 755

[22] F. Courtois, L. F. Olguin, G. Whyte, D. Bratton, W. T. S. Huck, C. Abell, F. Hollfelder, ChemBioChem 2008, 9, 439.

[23] T. Thorsen, R. W. Roberts, F. H. Arnold, S. R. Quake, Phys. Rev. Lett. 2001, 86, 4163.

[24] P. B. Umbanhowar, V. Prasad, D. A. Weitz, Langmuir 2000, 16, 347

[25] L. Cai, N. Friedman, X. S. Xie, Nature 2006, 440, 358.

[26] B. Zheng, L. S. Roach, R. F. Ismagilov, J. Am. Chem. Soc. 2003, $125,11170$.

[27] J. Leng, J. B. Salmon, Lab Chip 2009, 9, 24.

[28] J. R. Burns, C. Ramshaw, Lab Chip 2001, 1, 10.

[29] K. Ahn, J. Agresti, H. Chong, M. Marquez, D. A. Weitz, Appl. Phys. Lett. 2006, 88, 3.

[30] C. Priest, S. Herminghaus, R. Seemann, Appl. Phys. Lett. 2006 89, 134101.

[31] H. Song, M. R. Bringer, J. D. Tice, C. J. Gerdts, R. F. Ismagilov, Appl. Phys. Lett. 2003, 83, 4664.

[32] P. Kim, K. W. Kwon, M. C. Park, S. H. Lee, S. M. Kim, K. Y. Suh, Biochip J. 2008, 2, 1.

[33] A. Gunther, K. F. Jensen, Lab Chip 2006, 6, 1487.

[34] J. West, M. Becker, S. Tombrink, A. Manz, Anal. Chem. 2008, $80,4403$.

[35] G. F. Christopher, S. L. Anna, J. Phys. D 2007, 40, R319.

[36] T. Nisisako, T. Torii, T. Higuchi, Lab Chip 2002, 2, 24.

[37] D. R. Link, S. L. Anna, D. A. Weitz, H. A. Stone, Phys. Rev. Lett. 2004, 92, 054503.

[38] S. L. Anna, N. Bontoux, H. A. Stone, Appl. Phys. Lett. 2003, 82, 364.
[39] P. Garstecki, H. A. Stone, G. M. Whitesides, Phys. Rev. Lett. 2005, 94, 164501.

[40] A. S. Utada, A. Fernandez-Nieves, H. A. Stone, D. A. Weitz, Phys. Rev. Lett. 2007, 99, 094502.

[41] A. S. Utada, A. Fernandez-Nieves, J. M. Gordillo, D. A. Weitz, Phys. Rev. Lett. 2008, 100, 014502.

[42] K. J. Humphry, A. Ajdari, A. Fernandez-Nieves, H. A. Stone, D. A. Weitz, Phys. Rev. E 2009, 79, 056310.

[43] S. Q. Xu, Z. H. Nie, M. Seo, P. Lewis, E. Kumacheva, H. A. Stone, P. Garstecki, D. B. Weibel, I. Gitlin, G. M. Whitesides, Angew. Chem. 2005, 117, 734; Angew. Chem. Int. Ed. 2005, 44, 724.

[44] S. Sugiura, M. Nakajima, S. Iwamoto, M. Seki, Langmuir 2001, 17, 5562.

[45] K. C. van Dijke, K. Schroën, R. M. Boom, Langmuir 2008, 24, 10107.

[46] S. van der Graaf, C. Schroën, R. M. Boom, J. Membr. Sci. 2005, $251,7$.

[47] N. R. Beer, K. A. Rose, I. M. Kennedy, Lab Chip 2009, 9, 838.

[48] R. M. Lorenz, J. S. Edgar, G. D. M. Jeffries, D. T. Chiu, Anal. Chem. 2006, 78, 6433.

[49] M. Y. He, J. S. Edgar, G. D. M. Jeffries, R. M. Lorenz, J. P. Shelby, D. T. Chiu, Anal. Chem. 2005, 77, 1539.

[50] M. Y. He, J. S. Kuo, D. T. Chiu, Appl. Phys. Lett. 2005, 87, 031916.

[51] M. He, J. S. Kuo, D. T. Chiu, Langmuir 2006, 22, 6408.

[52] A. Bransky, N. Korin, M. Khoury, S. Levenberg, Lab Chip 2009, 9, 516.

[53] N. T. Nguyen, T. H. Ting, Y. F. Yap, T. N. Wong, J. C. K. Chai, W. L. Ong, J. Zhou, S. H. Tan, L. Yobas, Appl. Phys. Lett. 2007, 91, 084102

[54] S. H. Tan, S. M. S. Murshed, N. T. Nguyen, T. N. Wong, L. Yobas, J. Phys. D 2008, 41, 165501.

[55] A. Huebner, M. Srisa-Art, D. Holt, C. Abell, F. Hollfelder, A. J. Demello, J. B. Edel, Chem. Commun. 2007, 1218.

[56] S. Köster, F. E. Angile, H. Duan, J. J. Agresti, A. Wintner, C. Schmitz, A. C. Rowat, C. A. Merten, D. Pisignano, A. D. Griffiths, D. A. Weitz, Lab Chip 2008, 8, 1110.

[57] M. Srisa-Art, A. J. deMello, J. B. Edel, Anal. Chem. 2007, 79, 6682.

[58] Y. Schaerli, R. C. Wootton, T. Robinson, V. Stein, C. Dunsby, M. A. A. Neil, P. M. W. French, A. J. deMello, C. Abell, F. Hollfelder, Anal. Chem. 2009, 81, 302.

[59] A. Funfak, A. Brosing, M. Brand, J. M. Kohler, Lab Chip 2007, 7, 1132.

[60] J. Clausell-Tormos, D. Lieber, J. C. Baret, A. El-Harrak, O. J. Miller, L. Frenz, J. Blouwolff, K. J. Humphry, S. Koster, H. Duan, C. Holtze, D. A. Weitz, A. D. Griffiths, C. A. Merten, Chem. Biol. 2008, 15, 427.

[61] W. W. Shi, J. H. Qin, N. N. Ye, B. C. Lin, Lab Chip 2008, 8, 1432.

[62] J. S. Edgar, G. Milne, Y. Q. Zhao, C. P. Pabbati, D. S. W. Lim, D. T. Chiu, Angew. Chem. 2009, 121, 2757; Angew. Chem. Int. Ed. 2009, 48, 2719.

[63] J. S. Edgar, C. P. Pabbati, R. M. Lorenz, M. Y. He, G. S. Fiorini, D. T. Chiu, Anal. Chem. 2006, 78, 6948 .

[64] E. Brouzes, M. Medkova, N. Savenelli, D. Marran, M. Twardowski, J. B. Hutchison, J. M. Rothberg, D. R. Link, N. Perrimon, M. L. Samuels, Proc. Natl. Acad. Sci. USA 2009, 106, 14195.

[65] M. Chabert, J. L. Viovy, Proc. Natl. Acad. Sci. USA 2008, 105, 3191.

[66] J. F. Edd, D. Di Carlo, K. J. Humphry, S. Koster, D. Irimia, D. A. Weitz, M. Toner, Lab Chip 2008, 8, 1262.

[67] A. R. Abate, C. H. Chen, J. J. Agresti, D. A. Weitz, Lab Chip 2009, 9, 2628.

[68] C. H. Chen, A. R. Abate, D. Y. Lee, E. M. Terentjev, D. A. Weitz, Adv. Mater. 2009, 21, 3201. 
[69] J. Q. Boedicker, L. Li, T. R. Kline, R. F. Ismagilov, Lab Chip 2008, 8,1265 .

[70] F. Courtois, L. F. Olguin, G. Whyte, A. B. Theberge, W. T. S Huck, F. Hollfelder, C. Abell, Anal. Chem. 2009, 81, 3008.

[71] L. S. Roach, H. Song, R. F. Ismagilov, Anal. Chem. 2005, 77, 785 .

[72] Y. Liu, S.-Y. Jung, C. P. Collier, Anal. Chem. 2009, 81, 4922.

[73] M. Meier, J. Kennedy-Darling, S. H. Choi, E. M. Norstrom, S. S Sisodia, R. F. Ismagilov, Angew. Chem. 2009, 121, 1515; Angew. Chem. Int. Ed. 2009, 48, 1487.

[74] C. Holtze, A. C. Rowat, J. J. Agresti, J. B. Hutchison, F. E. Angile, C. H. J. Schmitz, S. Koster, H. Duan, K. J. Humphry, R. A. Scanga, J. S. Johnson, D. Pisignano, D. A. Weitz, Lab Chip 2008, 8, 1632.

[75] J. E. Kreutz, L. Li, L. S. Roach, T. Hatakeyama, R. F. Ismagilov, J. Am. Chem. Soc. 2009, 131, 6042.

[76] J.-C. Baret, F. Kleinschmidt, A. El Harrak, A. D. Griffiths, Langmuir 2009, 25, 6088.

[77] K. Wang, Y. C. Lu, J. H. Xu, G. S. Luo, Langmuir 2009, 25, 2153.

[78] L. Mazutis, J.-C. Baret, A. D. Griffiths, Lab Chip 2009, 9, 2665.

[79] L. Frenz, A. El Harrak, M. Pauly, S. Bégin-Colin, A. D. Griffiths, J. C. Baret, Angew. Chem. 2008, 120, 6923; Angew. Chem. Int. Ed. 2008, 47, 6817.

[80] Y. C. Tan, J. S. Fisher, A. I. Lee, V. Cristini, A. P. Lee, Lab Chip 2004, 4, 292.

[81] N. Bremond, A. R. Thiam, J. Bibette, Phys. Rev. Lett. 2008, 100, 024501.

[82] L. M. Fidalgo, C. Abell, W. T. S. Huck, Lab Chip 2007, 7, 984

[83] X. Niu, S. Gulati, J. B. Edel, A. J. deMello, Lab Chip 2008, 8 , 1837.

[84] A. R. Thiam, N. Bremond, J. Bibette, Phys. Rev. Lett. 2009, 102, 188304

[85] D. R. Link, E. Grasland-Mongrain, A. Duri, F. Sarrazin, Z. D. Cheng, G. Cristobal, M. Marquez, D. A. Weitz, Angew. Chem. 2006, 118, 2618; Angew. Chem. Int. Ed. 2006, 45, 2556.

[86] M. Chabert, K. D. Dorfman, J. L. Viovy, Electrophoresis 2005 , 26, 3706 .

[87] M. Zagnoni, J. M. Cooper, Lab Chip 2009, 9, 2652.

[88] L. Mazutis, J. C. Baret, P. Treacy, Y. Skhiri, A. F. Araghi, M. Ryckelynck, V. Taly, A. D. Griffiths, Lab Chip 2009, 9, 2902.

[89] C. N. Baroud, M. R. de Saint Vincent, J. P. Delville, Lab Chip 2007, 7, 1029

[90] F. Mostowfi, K. Khristov, J. Czarnecki, J. Masliyah, S. Bhattacharjee, Appl. Phys. Lett. 2007, 90, 184102.

[91] X. Z. Niu, F. Gielen, A. J. deMello, J. B. Edel, Anal. Chem. 2009, 81, 7321

[92] M. Zagnoni, C. N. Baroud, J. M. Cooper, Phys. Rev. E 2009, 80, 046303 .

[93] L. Frenz, J. Blouwolff, A. D. Griffiths, J. C. Baret, Langmuir 2008, 24, 12073.

[94] M. Prakash, N. Gershenfeld, Science 2007, 315, 832.

[95] M. J. Fuerstman, P. Garstecki, G. M. Whitesides, Science 2007, $315,828$.

[96] G. Cristobal, J. P. Benoit, M. Joanicot, A. Ajdari, Appl. Phys. Lett. 2006, 89, 034104.

[97] W. Engl, M. Roche, A. Colin, P. Panizza, A. Ajdari, Phys. Rev. Lett. 2005, 95, 208304.

[98] M. Schindler, A. Ajdari, Phys. Rev. Lett. 2008, 100, 044501.

[99] Y. Liu, R. F. Ismagilov, Langmuir 2009, 25, 2854.

[100] D. Chen, W. B. Du, Y. Liu, W. S. Liu, A. Kuznetsov, F. E. Mendez, L. H. Philipson, R. F. Ismagilov, Proc. Natl. Acad. Sci. USA 2008, 105, 16843.

[101] L. Frenz, K. Blank, E. Brouzes, A. D. Griffiths, Lab Chip 2009, 9, 1344.

[102] J. U. Shim, G. Cristobal, D. R. Link, T. Thorsen, Y. W. Jia, K. Piattelli, S. Fraden, J. Am. Chem. Soc. 2007, 129, 8825.

[103] T. Thorsen, S. J. Maerkl, S. R. Quake, Science 2002, 298, 580.
[104] J. N. Lee, C. Park, G. M. Whitesides, Anal. Chem. 2003, 75, 6544.

[105] A. Huebner, D. Bratton, G. Whyte, M. Yang, A. J. deMello, C. Abell, F. Hollfelder, Lab Chip 2009, 9, 692.

[106] C. H. J. Schmitz, A. C. Rowat, S. Koster, D. A. Weitz, Lab Chip 2009, $9,44$.

[107] P. Laval, A. Crombez, J. B. Salmon, Langmuir 2009, 25, 1836.

[108] J. F. Edd, K. J. Humphry, D. Irimia, D. A. Weitz, M. Toner, Lab Chip 2009, 9, 1859.

[109] P. Laval, N. Lisai, J. B. Salmon, M. Joanicot, Lab Chip 2007, 7, 829.

[110] W. H. Tan, S. Takeuchi, Proc. Natl. Acad. Sci. USA 2007, 104, 1146.

[111] H. Boukellal, S. Selimovic, Y. W. Jia, G. Cristobal, S. Fraden, Lab Chip 2009, 9, 331.

[112] N. R. Beer, K. A. Rose, I. M. Kennedy, Lab Chip 2009, 9, 841.

[113] K. Ahn, C. Kerbage, T. P. Hunt, R. M. Westervelt, D. R. Link, D. A. Weitz, Appl. Phys. Lett. 2006, 88, 024104.

[114] T. Franke, A. R. Abate, D. A. Weitz, A. Wixforth, Lab Chip 2009, 9, 2625.

[115] K. Zhang, Q. L. Liang, S. Ma, X. A. Mu, P. Hu, Y. M. Wang, G. A. Luo, Lab Chip 2009, 9, 2992.

[116] C. N. Baroud, J. P. Delville, F. Gallaire, R. Wunenburger, Phys. Rev. E 2007, 75, 046302.

[117] Y. F. Yap, S. H. Tan, N. T. Nguyen, S. M. S. Murshed, T. N. Wong, L. Yobas, J. Phys. D 2009, 42, 065503.

[118] J. C. Baret, O. J. Miller, V. Taly, M. Ryckelynck, A. El-Harrak, L. Frenz, C. Rick, M. L. Samuels, J. B. Hutchison, J. J. Agresti, D. R. Link, D. A. Weitz, A. D. Griffiths, Lab Chip 2009, 9, 1850.

[119] L. M. Fidalgo, G. Whyte, D. Bratton, C. F. Kaminski, C. Abell, W. T. S. Huck, Angew. Chem. 2008, 120, 2072; Angew. Chem. Int. Ed. 2008, 47, 2042.

[120] A. Liau, R. Karnik, A. Majumdar, J. H. D. Cate, Anal. Chem. 2005, 77, 7618 .

[121] N. Damean, L. F. Olguin, F. Hollfelder, C. Abell, W. T. S. Huck, Lab Chip 2009, 9, 1707.

[122] H. Song, H. W. Li, M. S. Munson, T. G. Van Ha, R. F. Ismagilov, Anal. Chem. 2006, 78, 4839.

[123] Y. P. Bai, X. M. He, D. S. Liu, S. N. Patil, D. Bratton, A. Huebner, F. Hollfelder, C. Abell, W. T. S. Huck, Lab Chip 2009, $9,44$.

[124] M. Srisa-Art, A. J. deMello, J. B. Edel, Phys. Rev. Lett. 2008, 101, 014502.

[125] M. Srisa-Art, E. C. Dyson, A. J. deMello, J. B. Edel, Anal. Chem. 2008, 80, 7063.

[126] M. Srisa-Art, D. K. Kang, J. Hong, H. Park, R. J. Leatherbarrow, J. B. Edel, S. I. Chang, A. J. deMello, ChemBioChem 2009, 10,1605

[127] G. Cristobal, L. Arbouet, F. Sarrazin, D. Talaga, J.-L. Bruneel, M. Joanicot, L. Servant, Lab Chip 2006, 6, 1140.

[128] F. Sarrazin, J.-B. Salmon, D. Talaga, L. Servant, Anal. Chem. 2008, 80, 1689.

[129] S. E. Barnes, Z. T. Cygan, J. K. Yates, K. L. Beers, E. J. Amis, Analyst 2006, 131, 1027.

[130] K. R. Strehle, D. Cialla, P. Rösch, T. Henkel, M. Köhler, J. Popp, Anal. Chem. 2007, 79, 1542.

[131] G. Wang, C. Lim, L. Chen, H. Chon, J. Choo, J. Hong, A. J. deMello, Anal. BioAnal. Chem. 2009, 394, 1827.

[132] F. Foret, P. Kusy, Electrophoresis 2006, 27, 4877.

[133] I. M. Lazar, J. Grym, F. Foret, Mass Spectrom. Rev. 2006, 25, 573.

[134] S. Koster, E. Verpoorte, Lab Chip 2007, 7, 1394.

[135] P. Hoffmann, M. Eschner, S. Fritzsche, D. Belder, Anal. Chem. 2009, 81, 7256 .

[136] D. Belder, Angew. Chem. 2009, 121, 3790; Angew. Chem. Int. Ed. 2009, 48, 3736. 
[137] G. T. Roman, M. Wang, K. N. Shultz, C. Jennings, R. T Kennedy, Anal. Chem. 2008, 80, 8231.

[138] L. M. Fidalgo, G. Whyte, B. T. Ruotolo, J. L. P. Benesch, F. Stengel, C. Abell, C. V. Robinson, W. T. S. Huck, Angew. Chem. 2009, 121, 3719; Angew. Chem. Int. Ed. 2009, 48, 3665.

[139] R. T. Kelly, J. S. Page, I. Marginean, K. Q. Tang, R. D. Smith, Angew. Chem. 2009, 121, 6964; Angew. Chem. Int. Ed. 2009, 48, 6832.

[140] J. Pei, Q. Li, M. S. Lee, G. A. Valaskovic, R. T. Kennedy, Anal. Chem. 2009, 81, 6558.

[141] S. J. Liu, Y. F. Gu, R. B. Le Roux, S. M. Matthews, D. Bratton, K. Yunus, A. C. Fisher, W. T. S. Huck, Lab Chip 2008, 8, 1937.

[142] C. X. Luo, X. J. Yang, O. Fu, M. H. Sun, Q. Ouyang, Y. Chen, H. Ji, Electrophoresis 2006, 27, 1977.

[143] Z. Han, W. Li, Y. Huang, B. Zheng, Anal. Chem. 2009, 81, 5840

[144] A. Huebner, L. F. Olguin, D. Bratton, G. Whyte, W. T. S. Huck, A. J. de Mello, J. B. Edel, C. Abell, F. Hollfelder, Anal. Chem. 2008, 80, 3890.

[145] K. Martin, T. Henkel, V. Baier, A. Grodrian, T. Schön, M. Roth, J. M. Köhler, J. Metze, Lab Chip 2003, 3, 202.

[146] H. Hufnagel, A. Huebner, C. Gulch, K. Guse, C. Abell, F. Hollfelder, Lab Chip 2009, 9, 1576.

[147] J. U. Shim, L. F. Olguin, G. Whyte, D. Scott, A. C. Babtie, C. Abell, F. Hollfelder, W. T. S. Huck, J. Am. Chem. Soc. 2009, 131, 15251.

[148] H. N. Joensson, M. L. Samuels, E. R. Brouzes, M. Medkova, M. Uhlen, D. R. Link, H. Andersson-Svahn, Angew. Chem. 2009 121, 2556; Angew. Chem. Int. Ed. 2009, 48, 2518.

[149] J. C. Gadd, C. L. Kuyper, B. S. Fujimoto, R. W. Allen, D. T. Chiu, Anal. Chem. 2008, 80, 3450.

[150] H. J. Kim, J. Q. Boedicker, J. W. Choi, R. F. Ismagilov, Proc. Natl. Acad. Sci. USA 2008, 105, 18188.

[151] J. Q. Boedicker, M. E. Vincent, R. F. Ismagilov, Angew. Chem. 2009, 121, 6022; Angew. Chem. Int. Ed. 2009, 48, 5908.

[152] Y. H. Zhan, J. Wang, N. Bao, C. Lu, Anal. Chem. 2009, 81, 2027.

[153] A. T. H. Hsieh, N. Hori, R. Massoudi, P. J. H. Pan, H. Sasaki, Y. A. Lin, A. P. Lee, Lab Chip 2009, 9, 2638.

[154] A. E. Sgro, P. B. Allen, D. T. Chiu, Anal. Chem. 2007, 79, 4845

[155] P. S. Dittrich, M. Jahnz, P. Schwille, ChemBioChem 2005, 6, 811.

[156] L. Mazutis, A. F. Araghi, O. J. Miller, J. C. Baret, L. Frenz, A. Janoshazi, V. Taly, B. J. Miller, J. B. Hutchison, D. Link, A. D. Griffiths, M. Ryckelynck, Anal. Chem. 2009, 81, 4813.

[157] A. J. de Mello, Lab Chip 2001, 1, 24N.

[158] R. Williams, S. G. Peisajovich, O. J. Miller, S. Magdassi, D. S Tawfik, A. D. Griffiths, Nat. Methods 2006, 3, 545.

[159] F. Diehl, M. Li, Y. P. He, K. W. Kinzler, B. Vogelstein, D. Dressman, Nat. Methods 2006, 3, 551.

[160] F. Diehl, M. Li, D. Dressman, Y. P. He, D. Shen, S. Szabo, L. A Diaz, S. N. Goodman, K. A. David, H. Juhl, K. W. Kinzler, B. Vogelstein, Proc. Natl. Acad. Sci. USA 2005, 102, 16368.

[161] J. Shendure, H. L. Ji, Nat. Biotechnol. 2008, 26, 1135.

[162] M. Li, F. Diehl, D. Dressman, B. Vogelstein, K. W. Kinzler, Nat. Methods 2006, 3, 95.

[163] P. Kumaresan, C. J. Yang, S. A. Cronier, R. G. Blazei, R. A. Mathies, Anal. Chem. 2008, 80, 3522.

[164] T. Kojima, Y. Takei, M. Ohtsuka, Y. Kawarasaki, T. Yamane, H. Nakano, Nucleic Acids Res. 2005, 33, e150.

[165] B. Vogelstein, K. W. Kinzler, Proc. Natl. Acad. Sci. USA 1999 96, 9236.

[166] S. Mohr, Y. H. Zhang, A. Macaskill, P. J. R. Day, R. W. Barber, N. J. Goddard，D. R. Emerson，P. R. Fielden，Microfluid. Nanofluid. 2007, 3, 611.

[167] A. Gonzalez, D. Ciobanu, M. Sayers, N. Sirr, T. Dalton, M. Davies, Biomed. Microdevices 2007, 9, 729.

[168] M. Curcio, J. Roeraade, Anal. Chem. 2003, 75, 1.

[169] F. Wang, M. A. Burns, Biomed. Microdevices 2009, 11, 1071.
[170] K. D. Dorfman, M. Chabert, J. H. Codarbox, G. Rousseau, P. de Cremoux, J. L. Viovy, Anal. Chem. 2005, 77, 3700.

[171] M. Chabert, K. D. Dorfman, P. de Cremoux, J. Roeraade, J. L. Viovy, Anal. Chem. 2006, 78, 7722.

[172] N. R. Beer, E. K. Wheeler, L. Lee-Houghton, N. Watkins, S. Nasarabadi, N. Hebert, P. Leung, D. W. Arnold, C. G. Bailey, B. W. Colston, Anal. Chem. 2008, 80, 1854.

[173] N. R. Beer, B. J. Hindson, E. K. Wheeler, S. B. Hall, K. A. Rose, I. M. Kennedy, B. W. Colston, Anal. Chem. 2007, 79, 8471.

[174] M. M. Kiss, L. Ortoleva-Donnelly, N. R. Beer, J. Warner, C. G. Bailey, B. W. Colston, J. M. Rothberg, D. R. Link, J. H. Leamon, Anal. Chem. 2008, 80, 8975.

[175] R. Tewhey, J. B. Warner, M. Nakano, B. Libby, M. Medkova, P. H. David, S. K. Kotsopoulos, M. L. Samuels, J. B. Hutchison, J. W. Larson, E. J. Topol, M. P. Weiner, O. Harismendy, J. Olson, D. R. Link, K. A. Frazer, Nat. Biotechnol. 2009, 27, 1025.

[176] L. Mugherli, O. N. Burchak, L. A. Balakireva, A. Thomas, F. Chatelain, M. Y. Balakirev, Angew. Chem. 2009, 121, 7775; Angew. Chem. Int. Ed. 2009, 48, 7639.

[177] T. Hatakeyama, D. L. Chen, R. F. Ismagilov, J. Am. Chem. Soc. 2006, $128,2518$.

[178] S. L. Poe, M. A. Cummings, M. P. Haaf, D. T. McQuade, Angew. Chem. 2006, 118, 1574; Angew. Chem. Int. Ed. 2006, 45, 1544

[179] P. Mary, V. Studer, P. Tabeling, Anal. Chem. 2008, 80, 2680.

[180] M. Rhee, M. A. Burns, Langmuir 2007, 24, 590.

[181] Y. Önal, M. Lucas, P. Claus, Chem. Eng. Technol. 2005, 28, 972.

[182] B. Ahmed, D. Barrow, T. Wirth, Adv. Synth. Catal. 2006, 348, 1043.

[183] B. Ahmed-Omer, D. A. Barrow, T. Wirth, Tetrahedron Lett. 2009, 50, 3352 .

[184] G. Dummann, U. Quittmann, L. Gröschel, D. W. Agar, O. Wörz, K. Morgenschweis, Catal. Today 2003, 79-80, 433.

[185] A. B. Theberge, G. Whyte, M. Frenzel, L. M. Fidalgo, R. C. R. Wootton, W. T. S. Huck, Chem. Commun. 2009, 6225.

[186] R. C. Wheeler, O. Benali, M. Deal, E. Farrant, S. J. F. MacDonald, B. H. Warrington, Org. Process Res. Dev. 2007, 11, 704.

[187] O. Benali, M. Deal, E. Farrant, D. Tapolczay, R. Wheeler, Org. Process Res. Dev. 2008, 12, 1007.

[188] C. A. Serra, Z. Chang, Chem. Eng. Technol. 2008, 31, 1099.

[189] W. Engl, R. Backov, P. Panizza, Curr. Opin. Colloid Interface Sci. 2008, 13, 206.

[190] S. W. Choi, I. W. Cheong, J. H. Kim, Y. Xia, Small 2009, 5, 454.

[191] M. Das, H. Zhang, E. Kumacheva, Annu. Rev. Mater. Res. 2006, 36, 117.

[192] R. K. Shah, J. W. Kim, J. J. Agresti, D. A. Weitz, L. Y. Chu, Soft Matter 2008, 4, 2303.

[193] R. K. Shah, H. C. Shum, A. C. Rowat, D. Lee, J. J. Agresti, A. S. Utada, L. Y. Chu, J. W. Kim, A. Fernandez-Nieves, C. J. Martinez, D. A. Weitz, Mater. Today 2008, 11, 18.

[194] Y. J. Zhao, X. W. Zhao, J. Hu, M. Xu, W. J. Zhao, L. G. Sun, C. Zhu, H. Xu, Z. Z. Gu, Adv. Mater. 2009, 21, 569.

[195] S. H. Kim, S. Y. Lee, G. R. Yi, D. J. Pine, S. M. Yang, J. Am. Chem. Soc. 2006, 128, 10897.

[196] Y. J. Zhao, X. W. Zhao, J. Hu, J. Li, W. Y. Xu, Z. Z. Gu, Angew. Chem. 2009, 121, 7486; Angew. Chem. Int. Ed. 2009, 48, 7350

[197] H. Zhang, E. Tumarkin, R. Peerani, Z. Nie, R. M. A. Sullan, G. C. Walker, E. Kumacheva, J. Am. Chem. Soc. 2006, 128, 12205.

[198] W. J. Jeong, J. Y. Kim, J. Choo, E. K. Lee, C. S. Han, D. J. Beebe, G. H. Seong, S. H. Lee, Langmuir 2005, 21, 3738.

[199] Q. Xu, M. Hashimoto, T. T. Dang, T. Hoare, D. S. Kohane, G. M. Whitesides, R. Langer, D. G. Anderson, H. David, Small 2009, 5, 1575 .

[200] M. Seo, Z. Nie, S. Xu, M. Mok, P. C. Lewis, R. Graham, E. Kumacheva, Langmuir 2005, 21, 11614.

[201] C. H. Chen, R. K. Shah, A. R. Abate, D. A. Weitz, Langmuir 2009, 25, 4320 . 
[202] Y. Wang, B. H. Guo, X. Wan, J. Xu, X. Wang, Y. P. Zhang, Polymer 2009, 50, 3361.

[203] J. Wan, A. Bick, M. Sullivan, H. A. Stone, Adv. Mater. 2008, 20 , 3314.

[204] Q. B. Xu, M. Hashimoto, T. T. Dang, T. Hoare, D. S. Kohane, G. M. Whitesides, R. Langer, D. G. Anderson, Small 2009, 5, 1575.

[205] C. H. Choi, J. H. Jung, D. W. Kim, Y. M. Chung, C. S. Lee, Lab Chip 2008, 8, 1544.

[206] S. Abraham, Y. H. Park, J. K. Lee, C. S. Ha, I. Kim, Adv. Mater. 2008, 20, 2177.

[207] J. W. Kim, A. S. Utada, A. Fernandez-Nieves, Z. B. Hu, D. A. Weitz, Angew. Chem. 2007, 119, 1851; Angew. Chem. Int. Ed. 2007, 46, 1819.

[208] Z. Nie, S. Xu, M. Seo, P. C. Lewis, E. Kumacheva, J. Am. Chem. Soc. 2005, 127, 8058.

[209] Y. Hennequin, N. Pannacci, C. P. De Torres, G. Tetradis-Meris, S. Chapuliot, E. Bouchaud, P. Tabeling, Langmuir 2009, 25, 7857.

[210] D. Lee, D. A. Weitz, Adv. Mater. 2008, 20, 3498.

[211] Z. Nie, W. Li, M. Seo, S. Xu, E. Kumacheva, J. Am. Chem. Soc. 2006, $128,9408$.

[212] T. Nisisako, T. Tonii, Adv. Mater. 2007, 19, 1489.

[213] N. Prasad, J. Perumal, C. H. Choi, C. S. Lee, D. P. Kim, $A d v$. Funct. Mater. 2009, 19, 1656.

[214] B. Wang, C. S. Ho, D. A. Weitz, ChemPhysChem 2009, 10, 641.

[215] M. Walser, R. Pellaux, A. Meyer, M. Bechtold, H. Vanderschuren, R. Reinhardt, J. Magyar, S. Panke, M. Held, Nucleic Acids Res. 2009, 37, e57.
[216] D. Mark, S. Haeberle, R. Zengerle, J. Ducree, G. T. Vladisavljevic, J. Colloid Interface Sci. 2009, 336, 634.

[217] H. Zhang, E. Tumarkin, R. M. A. Sullan, G. C. Walker, E. Kumacheva, Macromol. Rapid Commun. 2007, 28, 527.

[218] J. K. Oh, R. Drumright, D. J. Siegwart, K. Matyjaszewski, Prog. Polym. Sci. 2008, 33, 448.

[219] B. G. De Geest, J. P. Urbanski, T. Thorsen, J. Demeester, S. C. De Smedt, Langmuir 2005, 21, 10275.

[220] H. Zhang, X. J. Ju, R. Xie, C. J. Cheng, P. W. Ren, L. Y. Chu, J. Colloid Interface Sci. 2009, 336, 235.

[221] S. Sugiura, T. Oda, Y. Izumida, Y. Aoyagi, M. Satake, A. Ochiai, N. Ohkohchi, M. Nakajima, Biomaterials 2005, 26, 3327.

[222] E. Um, D. S. Lee, H. B. Pyo, J. K. Park, Microfluid. Nanofluid. 2008, 5,541 .

[223] L. Capretto, S. Mazzitelli, C. Balestra, A. Tosi, C. Nastruzzi, Lab Chip 2008, 8, 617.

[224] E. Amici, G. Tetradis-Meris, C. P. de Torres, F. Jousse, Food Hydrocolloids 2008, 22, 97.

[225] V. L. Workman, S. B. Dunnett, P. Kille, D. D. Palmer, Biomicrofluidics 2007, 1, 014105.

[226] V. L. Workman, S. B. Dunnett, P. Kille, D. D. Palmer, Macromol. Rapid Commun. 2008, 29, 165.

[227] W. Y. Chen, Y. J. Yang, C. Rinadi, D. Zhou, A. Q. Shen, Lab Chip 2009, 9, 2947.

[228] H. M. Evans, E. Surenjav, C. Priest, S. Herminghaus, R. Seemann, T. Pfohl, Lab Chip 2009, 9, 1933. 